\title{
Fate of floating plastic debris released along the coasts in a global ocean model
}

\author{
Chenillat Fanny ${ }^{1,}{ }^{*}$, Huck Thierry ${ }^{2}$, Maes Christophe ${ }^{1}$, Grima Nicolas ${ }^{2}$, Blanke Bruno ${ }^{2}$
}

\begin{abstract}
${ }^{1}$ Laboratoire d'Océanographie Physique et Spatiale (UMR 6523 LOPS), Univ Brest, CNRS, IRD, Ifremer, IUEM, Plouzané, France

${ }^{2}$ Laboratoire d'Océanographie Physique et Spatiale (UMR 6523 LOPS), Univ Brest, CNRS, IRD, Ifremer, IUEM, Plouzané, France
\end{abstract}

* Corresponding author : Fanny Chenillat, email address : fanny.chenillat@univ-brest.fr

\begin{abstract}
:
Marine plastic pollution is a global issue, from the shores to the open ocean. Understanding the pathway and fate of plastic debris is fundamental to manage and reduce plastic pollution. Here, the fate of floating plastic pollution discharged along the coasts is studied by comparing two sources, one based on river discharges and the other on mismanaged waste from coastal populations, using a Lagrangian numerical analysis in a global ocean circulation model. About $1 / 3$ of the particles end up in the open ocean and $2 / 3$ on beaches. The input scenario largely influences the accumulation of particles toward the main subtropical convergence zones, with the South Pacific and North Atlantic being mostly fed by the coastal population inputs. The input scenario influences the number of beached particles that end up in several coastal areas. Beaching occurs mainly locally, although a significant number of particles travel long distances, allowing for global connectivity.
\end{abstract}

\section{Highlights}

Rivers and coastal populations are key sources of marine plastic pollution. This pollution accumulates at the coasts $(\sim 2 / 3)$ and on the open ocean $(\sim 1 / 3)$. Littering of coastal populations explains better the pollution of subtropical gyres. Floating debris can travel long distances (up to several thousand kilometers). L Long-distance floating debris allows connectivity between remote coastal regions.

Keywords: Marine debris, Microplastics, Lagrangian analysis, Ocean surface pathways, Coastal pollution, Ocean connectivity 


\section{Introduction}

34 Marine pollution from plastics is a global issue and challenge (persistence of plastics at sea, consequences for marine life and potentially human health) that infests the ocean from coastal regions (e.g., Bergmann et al., 2017; Napper and Thompson, 2020) to the open sea (Barnes et al., 2009; Law et al., 2010; Cozar et al., 2014; van Sebille et al., 2015; Lebreton et al., 2018). According to Geyer et al. (2017), about half of the plastic debris produced is less dense than seawater and, consequently, is expected to float at the sea surface. This floating pollution either accumulates in the center of subtropical gyres (e.g., the Pacific Garbage Patch) or is discharged onto coasts and beaches. Transport of plastic is affected by a variety of physical processes (van Sebille et al., 2020; Dobler et al., 2019) characterized by different temporal and spatial variability. The pathways and fate of plastic debris in the oceans are still uncertain for many reasons, including a misperception of their sources, both in terms of quantity and distribution (Viatte et al., 2020). Indeed, observations are still limited, and the origins of the plastic collected at sea and along coasts remain a challenge to identify or evaluate.

Most of the projects on this issue are nowadays oriented toward a particular region or theme (Black et al., 2020), whereas plastic pollution must be considered as a global concern (Maes et al., 2019). Understanding the main pathway and fate of plastic debris remains fundamental to better manage and reduce plastic pollution from an environmental and economic perspective. Indeed, Lau et al. (2020) have shown that if no plastic pollution reduction strategy is undertaken, plastic pollution will triple by 2040. Despite the multiplicity of plastic pollution sources and the large uncertainties about the contribution of land-based plastic pollution

54 (Horton and Dixon, 2017), according to van Sebille et al. (2020), it is today recognized that coastal pollution is one of the largest sources of ocean plastic waste globally, with 5 to 12 million tons year ${ }^{-1}$ (Jambeck et al., 2015). As estimated by Faris and Hart (1994), 80\% of marine

57 litter enters the ocean by land, with the remaining $20 \%$ assumed to come from marine activities 
such as commercial and recreational fishing, cruises, and shipping (Lebreton et al., 2012). Given the scarcity of available data and observations on marine litter and plastic pollution (Galgani et al., 2021), numerical simulation can be used 'to fill in the gap' between these observations, and to test hypotheses about how plastic particles behave in the ocean" as explained by van Sebille et al. (2020). Indeed, numerical models are proper tools for understanding the transport and dispersion of plastic in the ocean (Hardesty et al., 2017), especially in a Lagrangian framework (van Sebille et al., 2018).

For instance, Lebreton et al. (2012) studied the relative contributions of plastics from impervious watersheds, coastal population and shipping inputs to different accumulation zones. In their study, they estimated that between $28 \%$ and $40 \%$ of the released particles were beached, depending on the input scenario.

Using a similar numerical methodology, we study hereafter the fate of floating plastic pollution in the ocean as discharged along the coasts. We compare two different source scenarios in the global ocean: one based on river inputs, and the other based on population density along the coasts and waste management. We use a Lagrangian numerical analysis in conjunction with surface currents from a reanalysis of a global ocean circulation model with a horizontal resolution of $1 / 12^{\circ}$. We discuss how the use of different scenarios helps to understand ocean connectivity and plastic pollution on a global scale. This study highlights the importance of considering accurate coastal inputs or sources, in particular littering from coastal populations, and provides insight into future strategies for monitoring and mitigating plastic debris. This study fits well within the main research priorities on marine plastic litter raised by the scientific community (Maximenko et al., 2019), in response to the G7 Science Ministers meeting in Berlin in October 2015 (Williamson et al., 2016), such as understand the pathways "establishing connections between sources and sinks for different types of debris", and understand the sinks, "including accumulation in remote locations". Section 2 presents the material and methods. Results for particles ending up at sea and in the convergence zones are given in section 3, whereas the specific analysis of particles ending up along the coast (beaching) is presented in section 4 . Section 5 is the concluding section. 
For this study, we use the sea surface current from the Global Ocean General Circulation Model GLORYS12V1, a leading global reanalysis of ocean circulation and physics (Lellouche et al., 2018). This reanalysis is part of the Copernicus Marine Environment Monitoring Service (CMEMS) with a new global eddy-resolving resolution and an ocean model with 50 vertical levels. The model component is the NEMO platform, forced at its surface by the ERA-Interim atmospheric reanalysis of the European Center for Medium-range Weather Forecast. These products are part of international efforts to give a better estimate of the global state of the oceans (von Schuckmann et al., 2016). This reanalysis covers the 1993-2018 altimetry era with a daily frequency, and provides not only a higher horizontal resolution compared to previous versions, but also improvements and corrections (Lellouche et al., 2018). In the following, we use the daily mean surface currents from the upper layer of the model with a thickness of $1 \mathrm{~m}$, from 1 January 1993 to 31 December 2015 (GLOBAL REANALYSIS PHY_001_030 product downloaded from https://resources.marine.copernicus.eu). The products of the Copernicus reanalysis being provided on a regular grid (A-grid in the classification of Arakawa and Lamb (1977)), we interpolated the velocities on the ORCA $1 / 12^{\circ}$ native C-grid to run the Lagrangian experiments.

107

\subsection{Coastal plastic source scenarios}

109

110 In this study, we compare two distinct scenarios of coastal sources of plastic particles: one 111 based on inputs from the world's main rivers and the other based on the coastal population

112 (Fig. S1), which we will identify as the river scenario and population scenario hereafter.

113 The river scenario comes from the model developed by Lebreton et al. (2017). This global

114 model of plastic inputs from rivers into the oceans is based on waste management, population

115 density and hydrological information. It estimates that about 2 million tons of plastic waste 
116 enters the ocean every year from 40,760 rivers. The 20 most polluting rivers are mainly located

117 along the western North Pacific and account for $71 \%$ of the total (Fig. 1). The North Indian and

118 North Atlantic basins account for $13 \%$ and $12 \%$ of the river inputs, respectively. Data were

119 downloaded from the global model inputs for annual midpoint estimates in Lebreton et al.

120 (2017) (data are available at figshare.com at doi:10.6084/m9.figshare.4725541).

121 The second scenario is that of mismanaged waste from the coastal population, which we we

122 refer to as the population scenario hereafter. This is actually a proxy of the mismanaged waste

123 released by the coastal population entering the ocean, as described in van Sebille et al. (2015):

124 it is computed as the human population within $200 \mathrm{~km}$ of the coast, scaled by the amount of

125 mismanaged plastic waste available to enter the ocean by country in 2010 (as referenced in

126 Jambeck et al. (2015) as 'mismanaged waste', based on the economic level of the countries)

127 In this scenario, plastic debris entering the ocean is more widely distributed (Fig. 1 and Fig. S1)

128 over 2633 coastal input positions. The west coast of the North Pacific accounts for $37 \%$ of the

129 total population's input, a relative contribution that is half that of the river input scenario. The

130 North Atlantic shorelines represent the second-highest source of plastic inputs with $21 \%$ of

131 total inputs (43\% more than river inputs). The North Indian basin represents $18 \%$ of the total

132 input. The Eastern Pacific, South Atlantic (east and west) and the Mediterranean Sea represent

133 larger sources of plastic ( $5 \%, 5 \%$ and $10 \%$, respectively) than in the river scenario $(<1 \%, 1 \%$ and

$134<1 \%$, respectively). Data were provided by Erik van Sebille (pers. comm., 2018) based on the

135 estimate of Jambeck et al. (2015) that 4.8-12.7 million tons of land-based plastic debris entered

136 the ocean in 2010, which is 2-6 times more than the river input on average.

137 Both scenarios are projected and discretized on our model grid. The finite number of total

138 particles released over the course of the experiment, and rounding to an integer number of

139 particles released each month in the source grid cells, reduces the effective number of source

140 points as follows. For the river scenario, the finite number of particles released each month

$141(20,000)$ reduces the effective number of source points to 522 grid cells (Fig. S1). There are very

142 large sources, with about 10 rivers releasing more than 500 particles per month (representing

143 altogether more than 58\% of the total), with the Yangtze River peaking at about 5000 particles

144 (25\% of the total). For the population scenario, out of the 2633 source points provided by Erik 
145 van Sebille (pers. comm., 2018) on a $1^{\circ} \times 1^{\circ}$ grid, the finite number of particles released each

146 month reduces the effective number of source grid cells to 1196 in our experiment (i.e., more

147 than twice that of the river scenario). There are no sources as extreme as in the river scenario;

148 the peak values are about 350 particles per month (barely $2 \%$ of the total), with 23 sources

149 releasing more than 100 particles per month (representing altogether $19 \%$ of the total).

150 Our objective is to diagnose how differences in input scenarios affect the fate of floating plastic

151 debris on a global scale. Thus, to make the two scenarios comparable, we choose to ignore the

152 difference in the total amount of plastic mass released in each scenario. For simplicity, we also

153 choose to ignore the temporal variability of coastal inputs in the two scenarios (e.g., river

154 discharge depends on rainfall variability). Thus, we consider that an equivalent mean amount of

155 plastic is released every month over the 23 years of simulation (1993-2015) from their coastal

156 positions (see next section) in both scenarios (river and population).

2.3. Lagrangian analysis

160 To study the fate and pathway of floating plastic debris in the global ocean, we use a Lagrangian 161 approach with the Ariane methodology (Blanke and Raynaud, 1997). As detailed in Maes et al.

162 (2018) or Dobler et al. (2019), the Ariane tool has been used so that the numerical particles are 163 horizontally advected by surface currents and do not experience vertical motion. The plastic 164 input data for both scenarios were gridded on the ORCA native grid at a resolution of $1 / 12^{\circ}$ at 165 the nearest ocean grid point, i.e., each source point is associated with a single grid cell of the 166 model. The initial positions of the particles are determined randomly within the grid cell. Note 167 that the population density proxy data set was available at a resolution of $1^{\circ} \times 1^{\circ}$; for this reason, 168 some final positions on the $1 / 12^{\circ}$ grid are not initialized exactly at the coast (as strictly defined 169 by the land-sea mask of the model) but near the coast. Two experiments are run according to 170 the coastal input scenario (see previous section) with equivalent total particle numbers:

$1715,589,080$ particles for the river scenario, and 5,571,720 particles for the population scenario 172 (the particle numbers are slightly different due to rounding to an integer number of particles 173 released each month). About 20,000 particles are thus released each month during the 23-year 
174 period from 1993 to 2015 (i.e., about 240,000 particles released per year). Particles released at

175 close locations within the same grid cell are subject to turbulent, seasonal and interannual

176 variability in the surface current that will lead to dispersion in their trajectories. The positions of

177 the particles are recorded with a monthly frequency. There are no explicit sinks in our approach

178 i.e., the released particles stay indefinitely at the surface in the model, still moving or stuck

179 along the coasts.

180

2.4. Particle behavior

182

We have diagnosed that particles can experience a different fate depending on their position and trajectory in the ocean:

- case $a$ : the particle leaves the coastline and travels within the ocean domain until the end of the experiment;

Note that, in absolute terms, cases $b$ and c could refer to a similar category of beaching and

197 thus to the same local pollution by plastic debris. However, we choose to distinguish these two cases because of the possible role of river mouth dynamics in such behavior.

\section{Open ocean convergence zones}


202 The particles are released continuously in both experiments. After a few years of Lagrangian

203 advection, the particles have spread almost all over the global ocean, from the coast to the

204 open ocean. Only a few regions remain free of particles: the Southern Ocean (due to the strong

205 northward Ekman transport), the Atlantic and Pacific equatorial regions (due to the strong

206 Ekman transport divergence), and the northern North Pacific and Chukchi Sea in the Arctic.

207 Figure 2 represents what could be roughly observed in terms of relative surface plastic pollution

208 from space at any given time. The two scenarios have similarities and differences (Fig. 2). In

209 both scenarios, surface plastics cover a large portion of the ocean between $45^{\circ} \mathrm{S}$ and $45^{\circ} \mathrm{N}$.

210 Particles seem to accumulate in bays, gulfs and seas surrounded by high-flow rivers (river

211 inputs) and densely populated coastlines (population inputs), e.g., in the Bay of Bengal, Gulf of

212 Guinea and China Sea (Reisser et al., 2013; Hinojosa and Thiel, 2009; Collignon et al., 2012;

213 Ryan, 2013), similarly in both scenarios. Other regions of accumulation are in the centers of the

214 subtropical gyres, regions known as CVZ (Convergence Zones), where plastic accumulates

215 through Ekman transport (Kubota, 1994; Maximenko et al., 2012; van Sebille, 2015), mainly in

216 the North Pacific and South Indian basins. Concentrations differ strongly between scenarios in

217 the South Atlantic, North Atlantic, South Pacific, and Arctic, but also in some coastal regions

218 (e.g., off Europe and Brazil). Another difference between the scenarios is the lower

219 concentration of particles in the equatorial Pacific and equatorial Atlantic in the river scenario

220 compared to the population scenario. These discrepancies between the scenarios are only due

221 to the relative input of particles (as the dynamics are the same in both experiments). Compared

222 to the in situ observations (see figure 1 "standardized data" of van Sebille et al., 2015), the

223 population scenario seems to show better agreement than the river scenario in terms of

224 relative amplitude and global distribution of surface plastic debris, mostly because of the higher

225 concentrations in the North Atlantic, South Atlantic and South Pacific CVZs. It should be

226 mentioned that no scenario exactly satisfies the relative concentrations of particles in the

227 different regions, especially since the syntheses of observations do not agree with each other.

228 This might be due to the fact that particles inputs are more widely distributed along the coast in

229 the population scenario than in the river scenario, as described in section 2.2.

230 
231 To determine the origins of these discrepancies and to untangle the fate and pathways of the

232 particles, now we modify the standard way of analyzing the fate of our particles. Instead of

233 merely looking at the position of particles at time $t$, which mixes particles of different ages

234 (such as Fig. 2), we choose to focus on the position of particles as a function of their age, i.e.,

235 the time elapsed since their release. We can thus follow a cohort of particle traveling from their

236 release position to their final position (Fig. 3). For this section, we focus on particles from case

237 a, i.e., particles ending up at sea. Since particles may be released at the same location at

238 different times, they may experience different dynamics; thus, such an analysis provides much

239 more consistent statistics on the plastic fate at the ocean surface. Figure 3 shows both the

240 quasi-initial position of the particles (i.e., one month after their release at the coast), and their

241 position after 22 years. The one-month-old particles have experienced one month of dynamics

242 and are still relatively close to their release position: such a representation gives a good

243 approximation of the initialization of particles in terms of position and concentration. It also

244 explicitly illustrates the main input differences between the scenarios: with the exception of the

245 tropical areas of the West Pacific and Northeast Indian Oceans, all other shores show significant

246 differences. As explained in section $2 b$, the population scenario is more widely spread,

247 especially in relation to the American, European and African population. Aost of the older

248 particles, which have been drifting with the currents for 20 vears, aggregate in the centers of

249 the gyres (while a few others are still drifting in highly dynamical regions such as the Agulhas

250 Eurrent or between the subtropical region of the South Indian-ocean and the southwestern

251 Pacific Ocean). After drifting with the currents for 20 years, the particles aggregate in the center

252 of the gyres (while others still drift in highly dynamical regions such as the Agulhas Current or

253 between the subtropical region of the South Indian Ocean and the southwestern Pacific Ocean).

254 Figure 3 highlights the importance of sources for accumulation in CVZs and, specifically, the

255 local influence of plastic pollution in the main gyres. By the term "local" we define the particles

256 that originate and end in the same region, as defined in figure S2. Whereas the North Pacific

257 and South Indian CVZs show quite similar concentrations and positions to the first order in both

258 scenarios, the concentration of particles in the South Pacific, North and South Atlantic CVZs is

259 much lower in the river scenario than in the population scenario. Indeed, the sources around 
the latter basins are much lower in the river scenario (Fig. 1) indicating that particles have mostly a local origin in many regions: particles initialized in one region are likely to stay in this region (e.g., North and South Atlantic, Southeast Pacific and Mediterranean). Outside the CVZs, particle concentrations are much lower (e.g., Maximenko et al., 2012; Law et al., 2014). In all basins, there is a very intense divergence of particles around the equator, due to the poleward Ekman transport associated with trade winds, such that particles from a sub-basin (North or South) are very likely to remain in their region of origin. As already highlighted by Lebreton et al. (2012), (i) because there is little exchange between hemispheres across the equator (except in a few coastal regions), and (ii) because the particles are mostly released in the Northern Hemisphere in the river scenario, there are far fewer particles that end up in the South Atlantic and South Pacific gyres than in their Northern Hemisphere counterparts. In the Indian basin, however, there is a seasonal north-south flush of particles along the eastern boundary (van der Mheen et al., 2020).

In addition to the local contribution of plastic pollution in the main gyres, the there is also a remote contribution allowed by the connectivity between sub-basins. This connectivity depends on the strength and extent of the attraction basins (Froyland et al., 2014). To study this connectivity from coastal regions to the open ocean, we determine the temporal accumulation of particles in the main gyres (Fig. 4) and establish a connectivity matrix from the coastal inputs of particles - i.e., the initial position of the particles to their final position at sea (Fig. 5) between the sub-regions defined in Fig. S2 (see also the mapped initial positions given in Figs. S3 and S4). To better capture the open-ocean signal of the particles attracted (Fig. 4), we limit the extension of the CVZs to their core - where particles accumulate over time (van Sebille et al., 2020) - and focus on the five main CVZs (see the colored boxes in Fig. 3). The slope of the curve indicates whether particles accumulate mostly in an attractive CVZ (positive slope), whether particles escape mostly from a leaky CVZ (negative slope), or whether an equilibrium is reached between sources and sinks in an attractive but still

287 leaky CVZ (null slope). Sinks may represent particles that move to other regions or that beach.

288 The rate at which a CVZ attracts particles provides an indication of the origin of the particles: 
289 the faster the early rate, the younger the particles are, the less they travel (and vice versa for a 290 slower rate).

291 In both river and population scenarios, the Indian CVZ is the region where plastics accumulate

292 the most and very rapidly: in 10 years up to $5.0 \%$ and $5.9 \%$ accumulate in the river and

293 population scenarios, respectively, with concentrations that continue to increase up to 15 years

294 of simulation. This results from the multiplicity of large sources converging to the Indian basin

295 (see IND.S in Figs. 5, S3 and S4), from local sources (all Indian) to remote sources (from the

296 Pacific and Atlantic shores). This is in line with Lebreton et al. (2012) who found that in the

297 Indian CVZ, the main contributors are Southeast Asia/Indonesia, Africa and India. Overall, the

298 South Indian is the most heterogeneously and widely impacted region, with particles coming

299 from all origins with the population inputs (except the Mediterranean) and from all over the

300 North Pacific and South Atlantic with the river inputs (Fig. 5). In this case, the particles likely

301 crossed the equator, for instance between the South and the North Indian during the

302 intermonsoon season, as recently documented by van der Mheen et al. (2020). This result

303 contrasts with that of Lebreton et al. (2012) who identified the greatest diversity of particle

304 origins in the Southeast Pacific. This discrepancy might be due to differences in input scenarios.

305 Interestingly, the North Indian feeds the Southeast Pacific (Fig. 5). This connection has already

306 been documented as the surface "superconvergence" pathway linking the south Indian Ocean

307 to the subtropical south Pacific gyre through the Great Australian Bight (Maes et al., 2018).

308 The North Pacific is the second region where plastics are accumulating the most and very

309 rapidly. The North Pacific CVZ starts to significantly attract particles after 2 years of simulation

310 and accumulates approximately the same number of particles in both scenarios, up to $\sim 4 \%$ in

311 about 5 years (Fig. 4). Particles traveled for 2 years from the Pacific and Indian shores before

312 ending up in the CVZ (see PAC.NE in Figs. 5, S3 and S4). An equilibrium is reached between

313 sources and sinks in the population scenario. However, in the river scenario, the equilibrium

314 shows a dip from year 7 to year 15 (i.e., 2000 to 2008), which is not observed in the population

315 scenario. This difference may be due to interannual variability in the dynamics linking one of

316 the sources to the CVZ. Indeed, in the river scenario, some of the sources involved in the

317 feeding of the North Pacific CVZ in the population scenario must be missing (e.g., from the 
318 Eastern Pacific). Toward the end of the simulation, after 15 years (i.e., from 2008), there is a

319 second increase in both scenarios, showing that the dynamics have favored the accumulation of

320 common sources - i.e., from North Pacific or South Indian - in the North Pacific CVZ.

321 Interestingly, the period 2000 to 2015 corresponds to a cool phase of the Pacific Decadal

322 Oscillation (PDO) and a positive phase of the North Pacific Gyre Oscillation (NPGO). Such

323 interannual variability is beyond the scope of this paper, but additional attention could be given

324 to linking particle accumulation to different modes of climate indices in future research

325 projects.

326 In the South Atlantic, there is a rapid accumulation of particles, followed by a slower increase

327 over the rest of the simulation with the population scenario (Fig. 4), due to the larger sources

328 all around the basin, mostly from Southeastern America (Figs. 3, S1 and S3). However, with

329 river inputs, the particle concentration in the South Atlantic CVZ increases slowly over the

330 whole period because particles come from very remote sources, from all over the Indian and

331 NW Pacific (see ATL.S. in Figs. 5 and S4).

332 Accumulations in the North Atlantic CVZ vary significantly according to the input scenario, as in

333 Lebreton et al. (2012). In the river scenario, very few particles accumulate, and an equilibrium

334 of $\sim 0.1 \%$ is rapidly reached (Fig. 4), with particles being attracted only from the local shores

335 (see ATL.N in Fig. 5). In the population scenario, a maximum is rapidly reached (1\% in less than a

336 year), followed by a decrease and a further increase toward an equilibrium of $\sim 1.1 \%$ in 5 years

337 (Fig. 4). In this case, there is a clear balance between the sources (North and South Atlantic

338 shores) and the open waters of the North Atlantic (Fig. 5), with the dispersion of particles from

339 the core in the North Atlantic waters.

340 In the South Pacific CVZ, particles accumulate very slowly and the maximum concentration of

341 about 0.1 and $1 \%$ is reached in 15 years (ten times slower than in the North Atlantic CVZ) with

342 river and population inputs, respectively. This is consistent with Lebreton et al. (2012) who

343 identified that "particles originating from South Atlantic and identified in the South Pacific Gyre

344 took more than 15 years to make the journey". In both scenarios, the locations of sources are

345 similar, but the concentration of inputs from the Eastern and Southwestern Pacific shores is

346 higher in the population scenario (see the PAC.SE position in Fig. 5), as in Lebreton et al. (2012). 
347 In terms of open ocean pollution (particles in case a, ending at sea), we evaluate that $28 \%$

348 ( $\sim 70,000$ particles) have a local origin in the river scenario, against 49\% ( 1,200,000 particles)

349 in the population scenario (these numbers are computed as the sum of the diagonal terms of

350 the connectivity matrix, Fig. 5). Thus, the remaining portions of the particles have a remote

351 origin (with our definition of regions), respectively $72 \%$ in the river scenario and $51 \%$ in the

352 population scenario. The NW Pacific shores represent the largest source of pollution at sea in

353 both scenarios (Fig. 1): particles reach mostly the South Indian (4.5 $10^{5}$ and $3.810^{5}$ particles,

354 i.e., $8 \%$ and $6.8 \%$ of the released particles) and the NE Pacific $\left(4.010^{5}\right.$ and $3.010^{5}$ particles, i.e.,

$3557.2 \%$ and $5.4 \%$ of the released particles), then the South Atlantic $\left(6.010^{4}\right.$ and $5.810^{4}$ particles,

356 i.e., $1.1 \%$ and $1.0 \%$ of the released particles) (numbers are given for river and population inputs,

357 respectively). Within these regions are the three main CVZ in terms of total number of particles

358 in cores. The NW Pacific is also a significant source of local pollution with $1.910^{5}$ and $1.210^{5}$

359 particles (i.e., $3.4 \%$ and $2.2 \%$ of released particles) for the river and population inputs,

360 respectively. The remaining number of particles $\left(3.710^{4}\right.$ and $1.810^{4}$ particles, i.e., $0.7 \%$ and

$3610.3 \%$ of released particles) ends up in the South Pacific (E and W) and North Indian.

362 In summary, these results emphasize the importance of the input of coastal sources in the total

363 accumulation and composition of the $5 \mathrm{CVZ}$, and the possible exchanges between these

364 regions. Our results show similarities and differences with those of Lebreton et al. (2012) (see

365 above for more details) who performed a similar analysis. Although we found the same $5 \mathrm{CVZ}$,

366 one of the most divergent results is that they find that northern CVZs accumulate more

367 particles than southern CVZs ( $25 \%$ in Northern Hemisphere CVZs compared to 10\% in

368 Southern Hemisphere CVZs), which is not our case (we find that $5 \%$ of the particles accumulate

369 in Northern Hemisphere CVZs versus 8\% in Southern Hemisphere CVZs). This discrepancy may

370 be due to differences in the input scenarios, the numerical tools (from surface current products

371 to Lagrangian experiments), and the methodology (definition of regions). However, it remains

372 difficult to validate the most realistic solution due to the lack of in situ observations in these

373 regions, especially in the Southern Hemisphere.

374 In total, in both scenarios, CVZs do not attract more than $20 \%$ of the total particles released at

375 the coast after a few years of simulation (Fig. 4). While the defined CVZs cover only a fraction of 
the patches in the gyres, i.e., the core, we found that only $29 / 45 \%$ of the particles end up in the open ocean, away from the coast, for the river and population scenarios, respectively (Fig. 6).

378 The majority of the particles thus end up along the coast, $71 / 55 \%$ respectively, and we now examine in detail the behavior of these beached particles.

\section{Beaching}

382

383

384

385

386

387

388

389

390

391

392

393

394

395

396

397

As noted in many previous studies (e.g., Maximenko et al., 2012; van Sebille et al., 2015), coastal deposit of plastic debris represents an important reservoir in the total budget. In the present estimation of the model dispersion, a significant proportion of the particles released at the coast does not end up in the open ocean (case a). Indeed, 36 and $43 \%$ of them end up on beaches (case b) while 34 and $11 \%$ travel alongshore (case $c$ ), in the river and population scenarios, respectively (Fig. 6). In total, $70 \%$ and $54 \%$ of the particles end up on the coasts (sum of case $b$ and case $c$ ) in the river and population scenarios, respectively. This is in good agreement with Lebreton et al. (2019) who showed that $67 \%$ of the world's plastic washed up on the coasts. Note that a small proportion of particles, $\sim 1 \%$, do not move from the grid cell where they were released. Details on these categories are given hereafter. Overall, the broad spatial spreading of beachings along the coasts (Fig. 7) is not strikingly different between the two scenarios (except for a few areas), especially when compared to the very contrasted input functions (Fig. S1).

In terms of sources, in both scenarios, coastal pollution originates mainly from the NW Pacific, North Indian and North Atlantic shorelines, mainly because these are the main sources of particles (Fig. 6). In the population scenario, most of the particles released from the Mediterranean shores actually beached. Depending on the region, the balance of open-oceanfate (case $a$ ) and coastal-fate (case b and $c$ ) is variable (Fig. S5). The following regions contribute more than $50 \%$ of the total coastal pollution, as diagnosed in cases $b$ and $c$ : North Indian (56\%), NW and SE Pacific (70\% and 96\%), North Atlantic (93\%) and Mediterranean (97\%) with the river scenario; and NW Pacific (57\%), North Atlantic (65\%) and Mediterranean (96\%) with the population scenario (Fig. S5). 
405 The origin of the particles that accumulate along the coast is mostly local (Figs. 7, 8, S6 and S7),

406 i.e., the initial and final positions are in the same region (this is also true for the particles that

407 stay on the coast in case c, Fig. S8). In both scenarios, we estimate that $85 \%(\sim 2,000,000$

408 particles) of the beached particles have a local origin (this number is computed as the sum of

409 the diagonal terms of the connectivity matrix, Fig. 8) likely due to coastal retention and coastal

410 recirculation. That is especially true for the NW Pacific, North Indian and North Atlantic in both

411 scenarios, and additionally for the Mediterranean in the population scenario. It is not surprising

412 that in the river scenario, the positioning of local beaching pollution corresponds to the river

413 areas, i.e., the Niger, the Amazon, the Ganges and rivers of the NW Pacific region (Mekong,

414 Yangtze, etc.) (Figs. 7 and S6). Rivers also appear to be hotspots for particle retention on coasts

415 (with 34\% of particles in case c, Fig. 6 and S8). With regard to the population scenario, where

416 sources are more widely distributed, beaching locations appear to be widespread along the

417 shores and, to a lesser extent, even in divergent regions such as coastal upwelling areas like

418 California, Peru or NW Africa (Fig. 7).

419 Coastal pollution is not, exclusively and totally, local, and the beaching process may in fact

420 occur after a long distance traveled. In both scenarios, we find that $\sim 27 \%$ of the beached

421 particles traveled less than $500 \mathrm{~km}, \sim 66 \%$ between $500 \mathrm{~km}$ and $5000 \mathrm{~km}$, and $7 \%$ more than

$4225000 \mathrm{~km}$ (Fig. 9). This highlights the shore-to-shore connectivity between remote regions (Fig. 8

423 and S9). For example, particles from the NW Pacific, which is the main source of coastal

424 pollution, can reach the Pacific, Indian or South Atlantic. Conversely, in the population scenario, 425 particles from the Atlantic shores can reach the West Pacific, South Indian, and also Arctic

426 shores. The Indian shores are also a source of beaching for older particles in the West Pacific, in 427 both scenarios.

428 To summarize, the impact of local pollution on beaching is even greater with population inputs 429 rather than with river inputs. This result deserves more attention and, because of uncertainties 430 and gaps in the observations of plastic waste, it remains challenging to predict the sources and 431 fate of plastics in coastal systems, as reported recently by Galgani et al. (2021). As for the 432 particles at sea in the CVZs, the differences between the two scenarios appear mainly in the 433 North Atlantic and SE Pacific, where the sources are very different (Fig. S1). In the North 
434 Atlantic, river inputs tend to stay locally on the coast (mostly from the Amazon and Niger),

435 whereas population inputs represent a high source of beached and offshore pollution (from

436 Europe and North America). In the SE Pacific, this local pollution is represented by a significant

437 proportion of offshore pollution with population inputs. The Mediterranean and NE Atlantic are

438 largely affected by beaching and coastal retention (Fig. 6 and Fig. S8) with population inputs.

439 Interestingly, these results highlight the disparity between regions in terms of plastic pollution:

440 some regions are strongly affected by coastal pollution (e.g., the North Pacific), due to coastal

441 retention and coastal recirculation, while others have a significant proportion of particles

442 staying offshore (e.g., North Indian and NW Pacific). In contrast to local pollution, there are a

443 significant number of beached particles that have traveled long distances in both scenarios and

444 this study highlights the main pathways of plastic debris between coastal regions and their

445 ability to travel long distances before ending up at the coast. Note that the geographic

446 differences found in the final positions of the particles between the two scenarios are directly

447 related to the location of the input sources and differences in concentration. Given these

448 differences between the input scenarios, the particles may encounter different oceanographic

449 features and dynamics that are likely to influence their final positions. However, the statistical

450 robustness of our approach relies on the use of several million particles to diagnose the main

451 pathways from initial positions to final positions, overcoming the effect of small scales.

452 Moreover, in our simulations, the particles do not sink, whereas in reality, such old particles

453 would most likely fall down the water column (Egger et al., 2020; Pabortsava and Lampitt,

454 2020) under the action of biology (biofouling, ingestion, or aggregation) (e.g., Kooi et al., 2017;

455 van Sebille et al., 2020).

456 A qualitative comparison with global beaching patterns, as compiled for instance in the

457 LITTERBASE database (https://litterbase.awi.de/litter, Tekman et al., 2018), generally shows

458 relatively good agreement, except for some regions. For instance, the database reports no

459 beachings along the east coast of Africa from Somalia to Mozambique, and along the coasts of

460 Oman and Yemen, probably due to a lack of observations.

461 A striking difference between the 2 scenarios is the complete absence of beachings along the

462 Pacific coast of South America. Coastal plastic and other debris reported along the Chilean coast 
suggest that the river input scenario is not sufficient to supply plastic particles to the South

464 Pacific, and in this respect the population scenario is more satisfactory (as reported in

465 LITTERBASE from Thiel et al. 2003; Hinojosa and Thiel, 2009; Hinojosa et al., 2011; Thiel et al.,

466 2013; Miranda-Urbina et al., 2015, Hidalgo-Ruiz et al., 2018). Similarly, the 2 scenarios differ

467 greatly along the east coast of America, where the river scenario leads to almost no beaching

468 north of Florida. This is not the case in LITTERBASE, confirming once again the need for

469 population inputs. Beaching patterns around the Indian basin and along the West Pacific coasts

470 are not significantly different between the 2 scenarios, and are in good agreement with

471 previously published results (van der Mheen et al., 2020). Beaching patterns around Australia

472 (PAC. SW in Fig. 8) differ from the 2 scenarios and the population scenario is in better

473 agreement with recent studies (Galaiduk et al. 2020) with significant input from local and

474 northwest Pacific shores.

\section{5}

476

477

478 The aim of this study is to investigate the pathway and fate of floating plastic debris, a key issue 479 that remains fundamental to better manage and reduce plastic pollution. We diagnose the fate 480 of plastic pollution discharged along the coasts by comparing two different types of sources in 481 the global ocean: one based on rivers and the other on the population density along the coasts.

482 We use a Lagrangian numerical analysis (forward particle tracking) based on surface currents 483 from reanalysis of a global ocean circulation model with a resolution of $1 / 12^{\circ}$. Our results 484 highlight the importance of the input scenario for the concentration of dispersed particles in 485 the open ocean, in specific subtropical convergence zones for instance, and the number of 486 particles beaching around oceanic basins, such as the Mediterranean Sea. The concentration of 487 particles at sea in certain convergence zones is particularly sensitive to the input scenario. More 488 precisely, population-related inputs are critical to feed convergence zones of the South Pacific 489 and North Atlantic. Connectivity between coastal sources and open ocean regions also indicates

490 that the Indian region is the most heterogeneous in terms of pollution with population-related 491 inputs. More generally, particles ending up at sea represent less than half of the particles 
492 released (and less than $20 \%$ in the convergence zones), whereas more than $50 \%$ end up at the 493 coast.

494 A large fraction of the total particles released ends up along the coast, between $54 \%$ in the 495 population scenario and $70 \%$ in the river scenario. The number of particles that beach in certain 496 areas also depends particularly on the input scenario, such as the European West Coast, the 497 Mediterranean Sea, and African East Coast with the population input. Rivers represent a large 498 source of local coastal pollution, probably due to the retention and recirculation of coastal waters. Regardless the input scenario, some regions are more subject to offshore pollution such as the South Atlantic and the NE Pacific, while others are more largely affected by coastal pollution (beaching) such as the NW Pacific, North Atlantic and Mediterranean shores. We have

502 found that particles can travel up to several thousand kilometers, allowing remote connectivity 503 between coastal regions. This property is of interest for the application to other types of 504 floating pollution or any conservative biogeochemical properties, or viruses and pathogens.

505 Our study remains an idealized case from several aspects, and from our point of view, the main 506 approximations are the "oversimplified" beaching process and the related dynamical processes.

507 Indeed, beaching of plastics is a complex process that is strongly influenced by small-scale 508 coastal ocean dynamics (Isobe et al., 2014), and by the local morphology of the coastline

509 (Zhang, 2017). Including Stokes-drift, waves or tides can also influence the number of particles 510 stuck to the coast, and increase it by more than three times (Dobler et al., 2019). Another key

511 point is the definition that can be given to the term "beaching". Using a $1 / 12^{\circ}$ eddy-resolving 512 ocean model, our definition is purely probabilistic since we define as beached particles those 513 that are at a certain distance from the coast (i.e., one grid point) (as similar studies e.g., van der 514 Mheen et al. (2020)).

515 Although this study is still based on available scenarios for plastic sources, it provides new 516 insights on connectivity between regions, on offshore pollution with CVZ composition and on 517 coastal pollution in terms of beaching. There are many ways to add complexity to these 518 processes. Indeed, for the sake of simplicity, we have neglected many key factors such as the 519 temporal/seasonal variability of coastal inputs that could change with rainfall (e.g., Lebreton et 520 al., 2017; van der Mheen et al., 2020), and also the significant worldwide increase in plastic 
521 inputs to the sea in relation to population growth and the rapid increase in plastic production

522 (Ostle et al., 2019). We have also ignored the contribution of pollution from maritime inputs

523 along shipping route or fishery activities (e.g., Lebreton et al., 2012). With the $1 / 12^{\circ}$ eddy-

524 resolving ocean model used, one might have expected to find particles crossing the Antarctic

525 Polar Front and reaching the Southern Ocean (Fraser et al., 2018), but it is likely that the

526 absence of extreme events and Stokes drift (driven by surface winds) does not allow such

527 connectivity. Finally, we focus on floating debris that could experience vertical motion in

528 response to physical or biological processes (van Sebille et al., 2020). It could be interesting to

529 implement models that allow interaction with the marine ecosystem - e.g., processes such as

530 ingestion by plankton and fish, sedimentation by biofouling (Kooi et al., 2017) which could

531 represent an important sink for particles toward the deep ocean (van Sebille et al., 2020).

532 Indeed, it has recently been documented by Egger et al. (2020) that we can find below the

533 surface ( $5 \mathrm{~m}$ depth) to 2,000 meters about $56 \%-80 \%$ of what is seen at the surface.

534 Marine plastic pollution represents an increasing threat to the environment. Because of their

535 serious detrimental effects on marine ecosystems (see examples in Napper and Thomson,

536 (2020)) and given the huge cost of removing this pollution from beaches (e.g., Burt et al., 2020;

537 Cruz et al., 2020; Napper and Thomson, 2020), it is today fundamental to understand the fate

538 and pathway of marine plastic debris. Such studies are needed to better inform and guide the

539 stakeholders involved in the reduction of plastic pollution and waste management decision

540 makers. However, a consensus is needed among researchers and a major step forward will be

541 to improve the quality of information available on beached marine debris, which would require

542 standardization of data sets (e.g., reporting metrics and sampling methods) (Serra-Gonçalves et

543 al., 2019; Galgani et al., 2021).

544

545 Acknowledgements

546 FC was supported by postdoctoral funding from CNRS/INSU. We thank gratefully Laurent

547 Lebreton and Erik van Sebille for providing their data sets for the source scenarios.

548

549 References 
551 Arakawa, A. and V.R. Lamb, 1977: Computational Design of the Basic Dynamical Process of the

552 UCLA General Circulation Model. Methods Computational Physics, 17, 173-265.

553 http://dx.doi.org/10.1016/B978-0-12-460817-7.50009-4

554

555 Barnes, D. K. A., F. Galgani, R.C. Thompson, and M. Barlaz, 2009: Accumulation and

556 fragmentation of plastic debris in global environments. Philosophical Transactions of the Royal

557 Society B: Biological Sciences 364, 1985-1998.

558

559

Bergmann, M., B. Lutz, M. B. Tekman, L. Gutow, 2017: Citizen scientists reveal: Marine litter

560 pollutes Arctic beaches and affects wild life, Marine Pollution Bulletin, 125, 1-2, 535-540,

561 https://doi.org/10.1016/j.marpolbul.2017.09.055.

562

563

Blanke, B., and S. Raynaud, 1997: Kinematics of the Pacific equatorial undercurrent: An eulerian and lagrangian approach from GCM results. J. Phys. Oceanogr., 27, 1038-1053.

565

566

Black J.E., D.E. Holmes and L.M. Carr, 2020: A Geography of Marine Plastics, Irish Geography,

Vol. 53, No. 1, DOI: 10.2014/igj.v53i1.1411.

568

569

Brach, L., P. Deixonne, M.-F. Bernard, A. ter halle, 2018: Anticyclonic eddies increase

570

accumulation of microplastic in the North Atlantic subtropical gyre. Marine Pollution Bulletin,

571 126:191-196, DOI: 10.1016/j.marpolbul.2017.10.077.

572

573 Cruz, C.J., J. J. Muñoz-Perez, M. I. Carrasco-Braganza, P. Poullet, P. Lopez-Garcia, A. Contreras,

574 R. Silva, 2020: Beach cleaning costs, Ocean \& Coastal Management, Volume 188, 105118,

575 doi.org/10.1016/j.ocecoaman.2020.105118.

576

577 Collignon A, Hecq J, Galgani F, Voisin P, Collard F, et al., 2012: Neustonic microplastic and

578 zooplankton in the North Western Mediterranean Sea. Mar. Pollut. Bull. 64: 861-864. 
580 Cózar, A., F. Echevarría, J. I. González-Gordillo, X. Irigoien, B. Úbeda, S. Hernández-León, Á. T.

581 Palma, S. Navarro, J. García-de-Lomas, A. Ruiz, M. L. Fernández-de-Puelles, and C. M. Duarte,

582 2014: Plastic debris in the open ocean. PNAS 2014111 (28) 10239-10244,

583 doi:10.1073/pnas.1314705111.

584

585 Dobler, D., T. Huck, C. Maes, N. Grima, B. Blanke, E. Martinez, F. Ardhuin, 2019: Large impact of 586 Stokes drift on the fate of surface floating debris in the South Indian Basin. Mar. Pollut. Bull., 587 148, 148, 202-209, doi: 10.1016/j.marpolbul.2019.07.057.

588

589

Egger, M., Sulu-Gambari, F. \& Lebreton, L. 2020: First evidence of plastic fallout from the North 590 Pacific Garbage Patch. Sci Rep 10, 7495. https://doi.org/10.1038/s41598-020-64465-8.

591

592

Faris, J., Hart, K., 1994: Seas of Debris: A Summary of the Third International Conference on Marine Debris. N.C. Sea Grant College Program and NOAA.

Froyland, G., R. M. Stuart, and E. van Sebille, 2014: How well connected is the surface of the global ocean? Chaos, 24, 033126.

Galgani, F., Brien, A.So., Weis, J. et al., 2021. Are litter, plastic and microplastic quantities increasing in the ocean?. Micropl.\&Nanopl. 1, 2. https://doi.org/10.1186/s43591-020-00002-8 600 made. Science Advances, 3, 1-5, 19 July2017.

603

604 Hardesty B D, Harari J, Isobe A, Lebreton L C M, Maximenko N A, Potemra J, van Sebille E, 605 Vethaak A D and Wilcox C, 2017: Using numerical model simulations to improve the 606 understanding of micro-plastic distribution and pathways in the marine environment. Front. 607 Mar. Sci. 4:30, doi: 10.3389/fmars.2017.00030. 
609 Hidalgo-Ruz, V., Honorato-Zimmer, D., Gatta- Rosemary, M., Nuñez, P., Hinojosa, I.A. and Thiel, 610 M., 2018: Spatio-temporal variation of anthropogenic marine debris on Chilean beaches.

611 Marine Pollution Bulletin, 126, 516-524. https:// doi.org/10.1016/j.marpolbul.2017.11.014.

614 Hinojosa I, Thiel M, 2009: Floating marine debris in fjords, gulfs and channels of southern Chile.

615 Mar. Pollut. Bull. 58, 341-350.

616

617 Hinojosa, I. A., Rivadeneira, M.M., Thiel, M., 2011: Temporal and spatial distribution of floating 618 objects in coastal waters of central-southern Chile and Patagonian fjords, Continental Shelf

619 Research, 31, Issues 3-4, 172-186, doi.org/10.1016/j.csr.2010.04.013.

621 Isobe, A., Kubo, K., Tamura, Y., Kako, S., Nakashima, E., and Fujii, N., 2014: Selective transport of 622 microplastics and mesoplastics by drifting in coastal waters, Marine Pollution Bulletin, 89, 324623 330, https://doi.org/10.1016/j.marpolbul.2014.09.041.

Jambeck, J. R., R. Geyer, C. Wilcox, T. R. Siegler, M. Perryman, A. Andrady, R. Narayan, and K. L. Law, 2015: Plastic waste inputs from land into the ocean. Science, 347, (6223) 768-771, DOI: 10.1126/science.1260352.

628

Kooi M., E.H. van Nes, M. Scheffer and A.A. Koelmans, 2017: Ups and Downs in the Ocean:

630 Effects of Biofouling on Vertical Transport of Microplastics. Environ. Sci. Technol., 51, 631 7963-7971. DOI: 10.1021/acs.est.6b04702.

632

633 Kubota, M., 1994: A Mechanism for the Accumulation of Floating Marine Debris North of 634 Hawaii. J. Phys. Oceanogr., 24, 1059-1064, doi: 10.1175/1520-0485. 635 
636 Lau W.W.Y, Y. Shiran, R.M. Bailey et al., 2020: Evaluating scenarios toward zero plastic

637 pollution. Science, 369, 6510, 1455-1461, DOI: 10.1126/science.aba9475.

638

639 Law K. L., S. E. Morét-Ferguson, D. S. Goodwin, E. R. Zettler, E. DeForce, T. Kukulka and G.

640 Proskurowski, 2014: Distribution of surface plastic debris in the Eastern Pacific Ocean from an

641 11-year data set. Environ. Sci. Technol. 48, 4732-4738.

642

643 Law K. L., S.E. Morét-Ferguson, N. A. Maximenko, G. Proskurowski, E. E. Peacock, J. Hafner and 644 C. M. Reddy, 2010: Plastic accumulation in the North Atlantic subtropical gyre. Science, 329

645 1185-1188.

646

647

Lebreton, L.C.M., S. Greer, and J. Borrero, 2012: Numerical modelling of floating debris in the

648 World's Ocean. Mar. Pollut.Bull., 64, 653-661.

649

650

Lebreton, L.C.M, B. Slat, F. Ferrari, B. Sainte-Rose et al., 2018: Evidence that the Great Pacific

651

Garbage Patch is rapidly accumulating plastic, Nature Scientific report, 8:4666,

652

DOI:10.1038/s41598-018-22939-w.

653

654

Lebreton, L.C.M., J. van der Zwet, J.-W. Damsteeg, B. Slat, A. Andrady, J. Reisser, 2017: River

655

plastic emissions to the world's oceans. Nature Communications, 8, 15611, DOI:

656

10.1038/ncomms15611.

657

658

Lellouche, J.-M.; Greiner, E.; Le Galloudec, O.; Garric, G.; Regnier, C.; Drevillon, M.; Benkiran,

M.; Testut, C.-E.; Bourdalle-Badie, R.; Gasparin, F.; et al., 2018: Recent updates to the

660

Copernicus Marine Service global ocean monitoring and forecasting real-time 1/12 high-

661

resolution system. Ocean Sci., 14, 1093-1126, https://doi.org/10.5194/os-14-1093-2018.

662

663 Maes, C., and B. Blanke, 2015: Tracking the origins of plastic debris across the Coral Sea: A case 664 study from the Ouvéa Island, New Caledonia. Mar. Pollut. Bull., 97, (1-2) 16-168. 
666 Maes, C., N. Grima, B. Blanke, E. Martinez, T. Paviet-Salomon, T. Huck, 2018: A surface "super667 convergence" pathway connecting the South Indian Ocean to the subtropical South Pacific gyre. 668 Geophysical Research Letters, 45, (4) 1915-1922, 2017GL076366, doi: 10.1002/2017GL076366. 669

670 Maes T., J. Perry, K. Alliji, C. Clarke, S.N.R. Birchenough, 2019: Shades of grey: Marine litter 671 research developments in Europe, Marine Pollution Bulletin, 146, 274-281, DOI:

672 10.1016/j.marpolbul.2019.06.019.

673

674 Maximenko, N.A., J. Hafner, and P. Niiler, 2012: Pathways of marine debris from trajectories of 675 Lagrangian drifters. Marine Pollution Bulletin, 65 (1-3), 51-62, 676 doi:10.1016/j.marpolbul.2011.04.016.

677

678 Maximenko Nikolai, Corradi Paolo, Law Kara Lavender, Van Sebille Erik, Garaba

679 Shungudzemwoyo P., et al., 2019: Toward the Integrated Marine Debris Observing System.

680 Frontiers in Marine Science, 6, 447. DOI=10.3389/fmars.2019.00447

681

682 Miranda-Urbina, D., Thiel, M., Luna-Jorquera, G., 2015: Litter and seabirds found across a 683 Iongitudinal gradient in the South Pacific Ocean, Marine Pollution Bulletin, Volume 96, Issues 1684 2, Pages 235-244, doi.org/10.1016/j.marpolbul.2015.05.021.

685

686 Napper, I. E. and R. C. Thompson, 2020: Plastic Debris in the Marine Environment: History and 687 Future Challenges. Global Challenges 4,1900081. DOI:10.1002/gch2.201900081.

688

689

Ostle, C., Thompson, R.C., Broughton, D. et al., 2019: The rise in ocean plastics evidenced from 690 a 60-year time series. Nat Commun 10, 1622. https://doi.org/10.1038/s41467-019-09506-1 691

692 Pabortsava, K., Lampitt, R.S., 2020: High concentrations of plastic hidden beneath the surface of 693 the Atlantic Ocean. Nat Commun 11, 4073, doi: 10.1038/s41467-020-17932-9. 
695 Reisser J, Shaw J, Wilcox C, Hardesty B, Proietti M, 2013: Marine plastic pollution in the waters 696 around Australia: Characteristics, concentrations and pathways. PloS one 8,

697 doi:10.1371/journal.pone.0080466.

698

699 Ryan, P.G., 2013: A simple technique for counting marine debris at sea reveals steep litter

700 gradients between the Straits of Malacca and the Bay of Bengal. Mar. Pollut. Bull. 69, 128-136,

701 doi: 10.1016/j.marpolbul.2013.01.016.

702

703 Serra-Gonçalves, C., Lavers, J. L., \& Bond, A. L., 2019: Global Review of Beach Debris Monitoring

704 and Future Recommendations. Environmental Science \& Technology, 53(21), 12158-12167.

705 https://doi.org/10.1021/acs.est.9b01424

706

707

Tekman, M. B.; Gutow, L.; Macario, A.; Haas, A.; Walter, A.; Bergmann, M. 2018: LITTERBASE;

708 Alfred Wegener Institute for Polar and Marine Research: Bremerhaven, Germany, 2018.

709 http://litterbase.awi. de/interaction_detail (accessed September 2020).

710

711 Thiel, M., Hinojosa, I. A., Miranda, L., Pantoja, J. F., Rivadeneira, M. M., Vásquez, N., 2013:

712 Anthropogenic marine debris in the coastal environment: A multi-year comparison between

713 coastal waters and local shores, Marine Pollution Bulletin, 71, Issues 1-2, 307-316,

714 doi.org/10.1016/j.marpolbul.2013.01.005.

715

716 Thiel, M., Hinojosa, I., Vásquez, N., Macaya, E., 2003: Floating marine debris in coastal waters of

717 the SE-Pacific (Chile), Marine Pollution Bulletin, 46, Issue 2, 224-231, doi.org/10.1016/S0025-

$718326 \times(02) 00365-X$

719

720 van der Mheen, M., E. van Sebille, C. Pattiaratchi, 2020: Beaching patterns of plastic debris

721 along the Indian Ocean rim. Ocean Science Discussions, DOI: 10.5194/os-2020-50. 
723

724

725

726

727

728

729

730

731

732

733

734

735

736

737

738

739

740

741

742

743

744

745

746

747

748

749

750

van Sebille E., 2015: The oceans' accumulating plastic garbage. Phys. Today, 68, 60-1.

van Sebille, E., M. H. England, and G. Froyland, 2012: Origin, dynamics and evolution of ocean garbage patches from observed surface drifters. Environ. Res. Lett., 7, 044040, 6pp. http://iopscience.iop.org/article/10.1088/1748-9326/7/4/044040.

van Sebille, E., C. Wilcox, L. Lebreton, N. Maximenko, B.D. Hardesty, J.A. Van Franeker, M. Eriksen, D. Siegel, F. Galgani, and K. L. Law, 2015: A global inventory of small floating plastic debris. Environ. Res. Lett., 10, 124006, 12pp, doi: 10.1088/1748-9326/10/12/124006 .

van Sebille, E., et al., 2020: The physical oceanography of the transport of floating marine debris. Environmental Research Letters, 15, 023003, doi: 10.1088/1748-9326/ab6d7d.

Karina von Schuckmann, Pierre-Yves Le Traon, Enrique Alvarez-Fanjul, Lars Axell, et al., 2016: The Copernicus Marine Environment Monitoring Service Ocean State Report, Journal of Operational Oceanography, 9:sup2, s235-s320, DOI: 10.1080/1755876X.2016.1273446

Viatte, C., Clerbaux, C., Maes, C., Daniel, P., Garello, R., Safieddine, S., Ardhuin, F., 2020: Air Pollution and Sea Pollution Seen from Space. Surv. Geophys., doi:10.1007/s10712-020-09599-0. https://doi.org/10.1007/s10712-020-09599-0.

Williamson, P., Smythe-Wright, D., and Burkill, P., Eds., 2016: Future of the Ocean and its Seas: a non-governmental scientific perspective on seven marine research issues of G7 interest. ICSUIAPSO-IUGG-SCOR, Paris.

Zhang, H., 2017: Transport of microplastics in coastal seas, Estuarine, Coastal and Shelf Science, 199, 74-86, https://doi.org/10.1016/j.ecss.2017.09.032. 

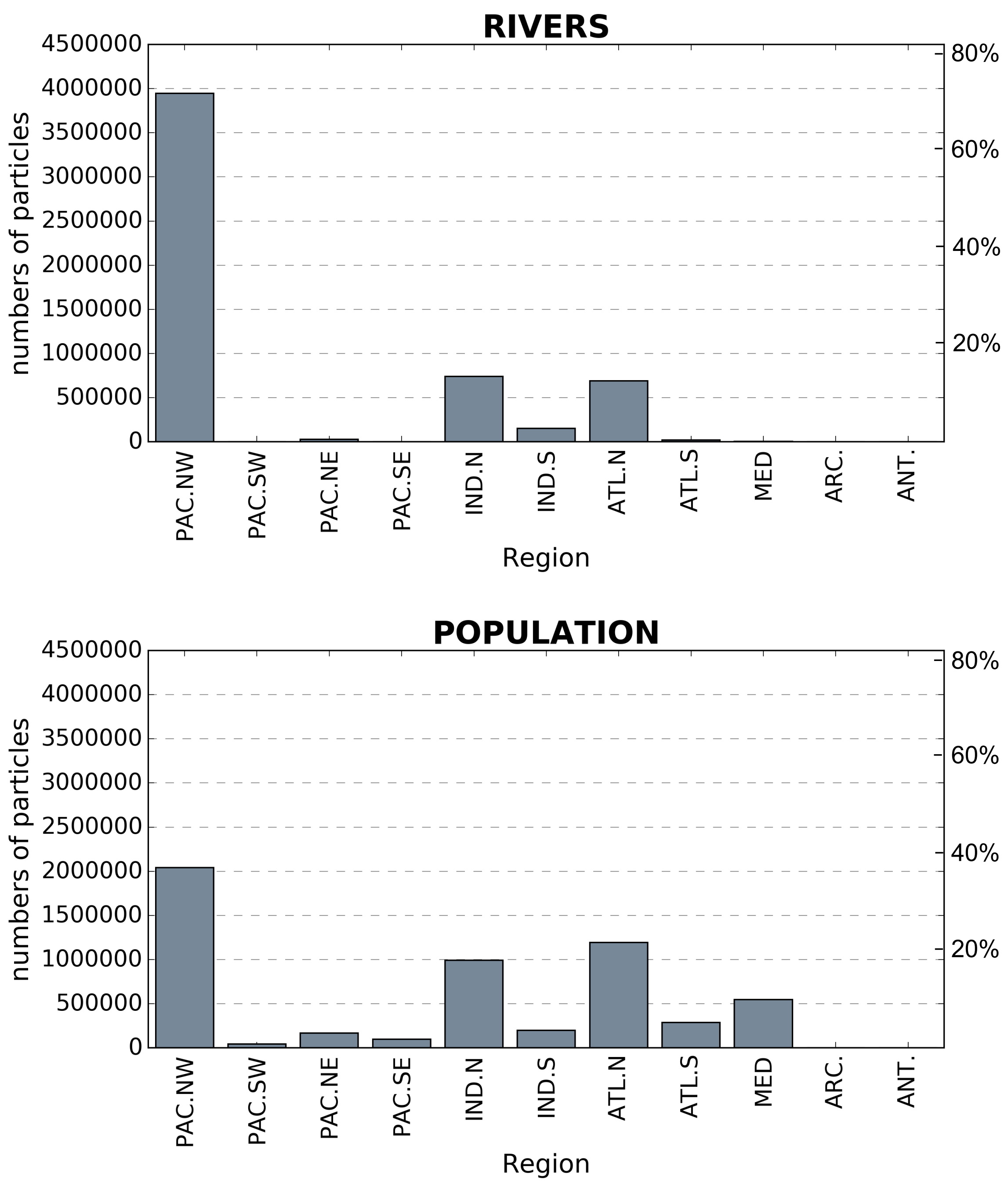

Fig. 1: Total number of particles released in each region in the Lagrangian experiments in the river scenario (top) and the population scenario (i.e., mismanaged waste from the coastal population) (bottom) (maps of the input positions are given in Fig. S1 and oceanic regions are defined in Fig. S2). A total of 5,589,080 and 5,571,720 particles are released in the river and population scenarios, respectively. Percentages on the right are given relatively to the total particles released. 

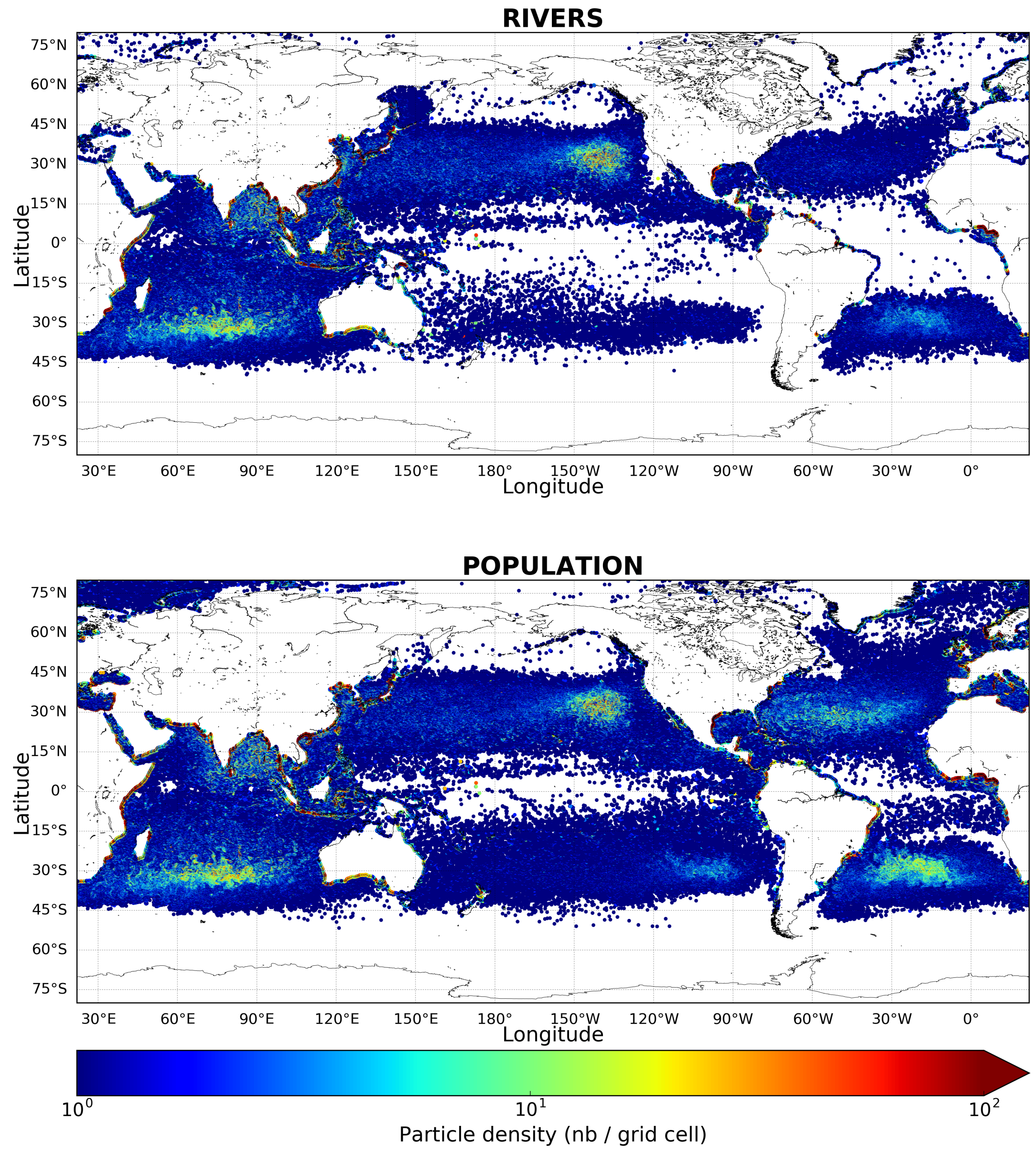

Fig. 2: Number of particles per model grid cell at the end of the model simulations (year 23) in the river scenario (top) and the population scenario (i.e., mismanaged waste from the coastal population) (bottom). 
RIVERS

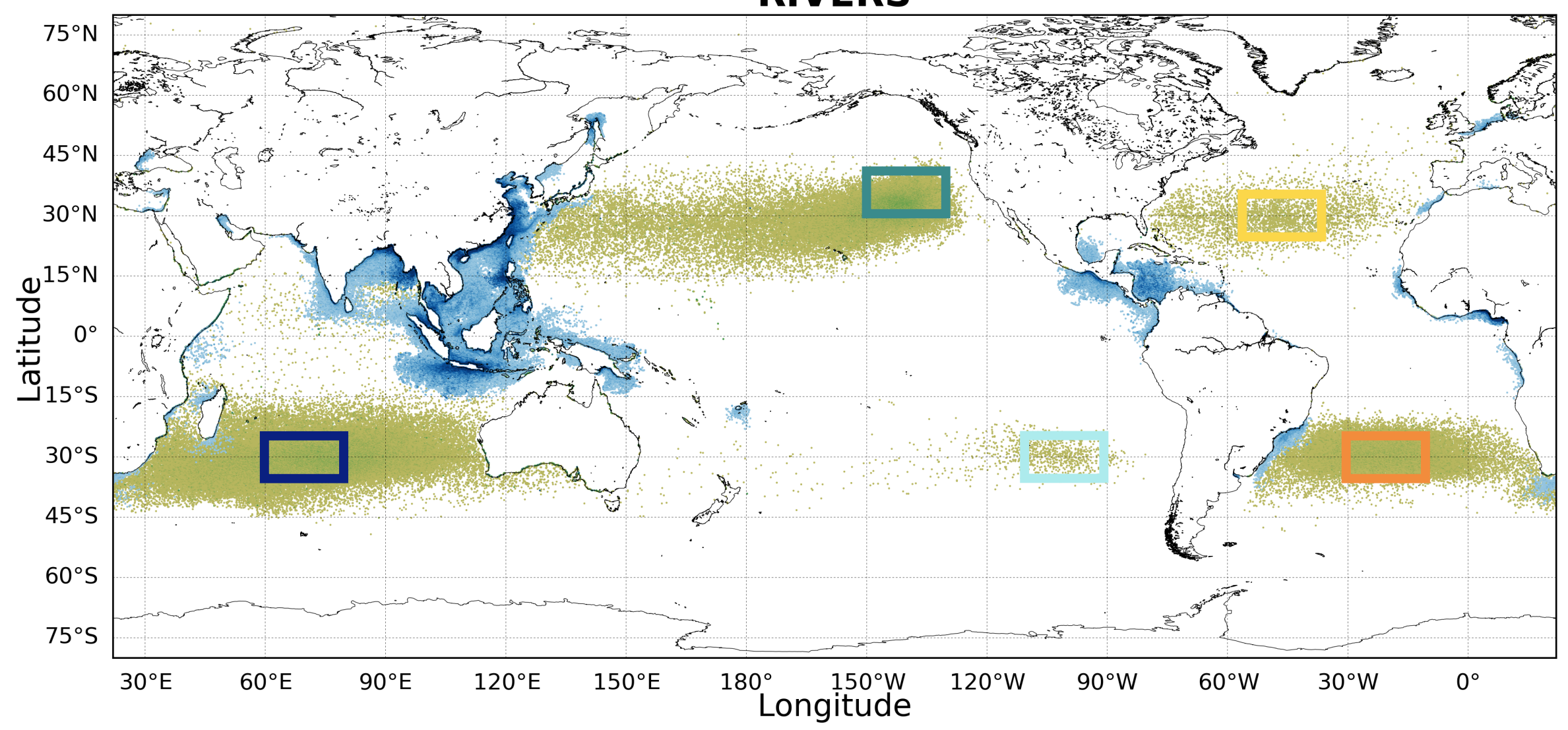

POPULATION

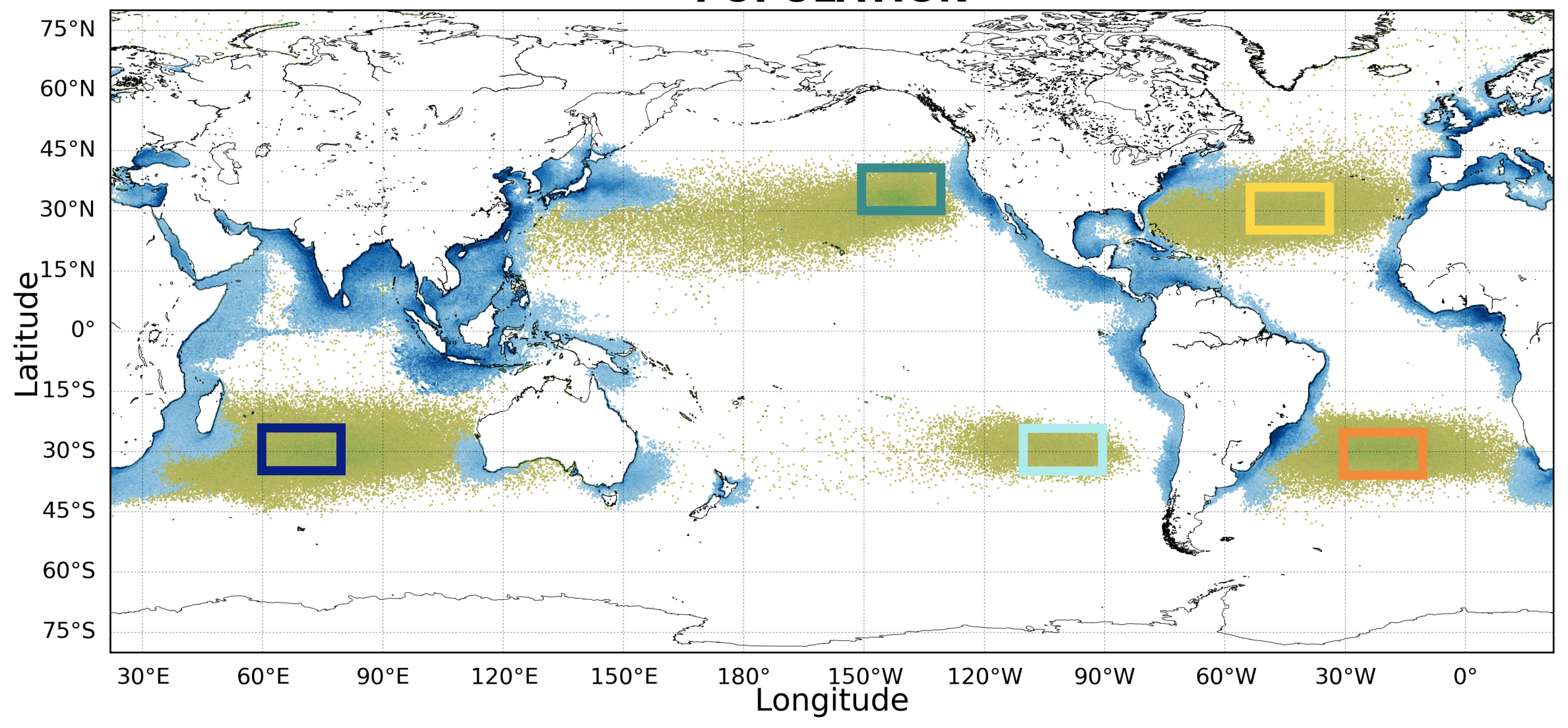

$10^{1}$

Fig. 3: Number of particles per model grid cell at different ages in the river scenario (top) and the population scenario (i.e., mismanaged waste from the coastal population) (bottom): particles aged 1 month (blue colorbar) and particles aged 22 years (green colorbar). Note that the total number of 1-monthold particles is 22 times higher than the number of 22-year-old particles (released during the first year of the Lagrangian experiment). The colored boxes represent the center of the five main convergence zones (CVZs). 


\section{RIVERS}

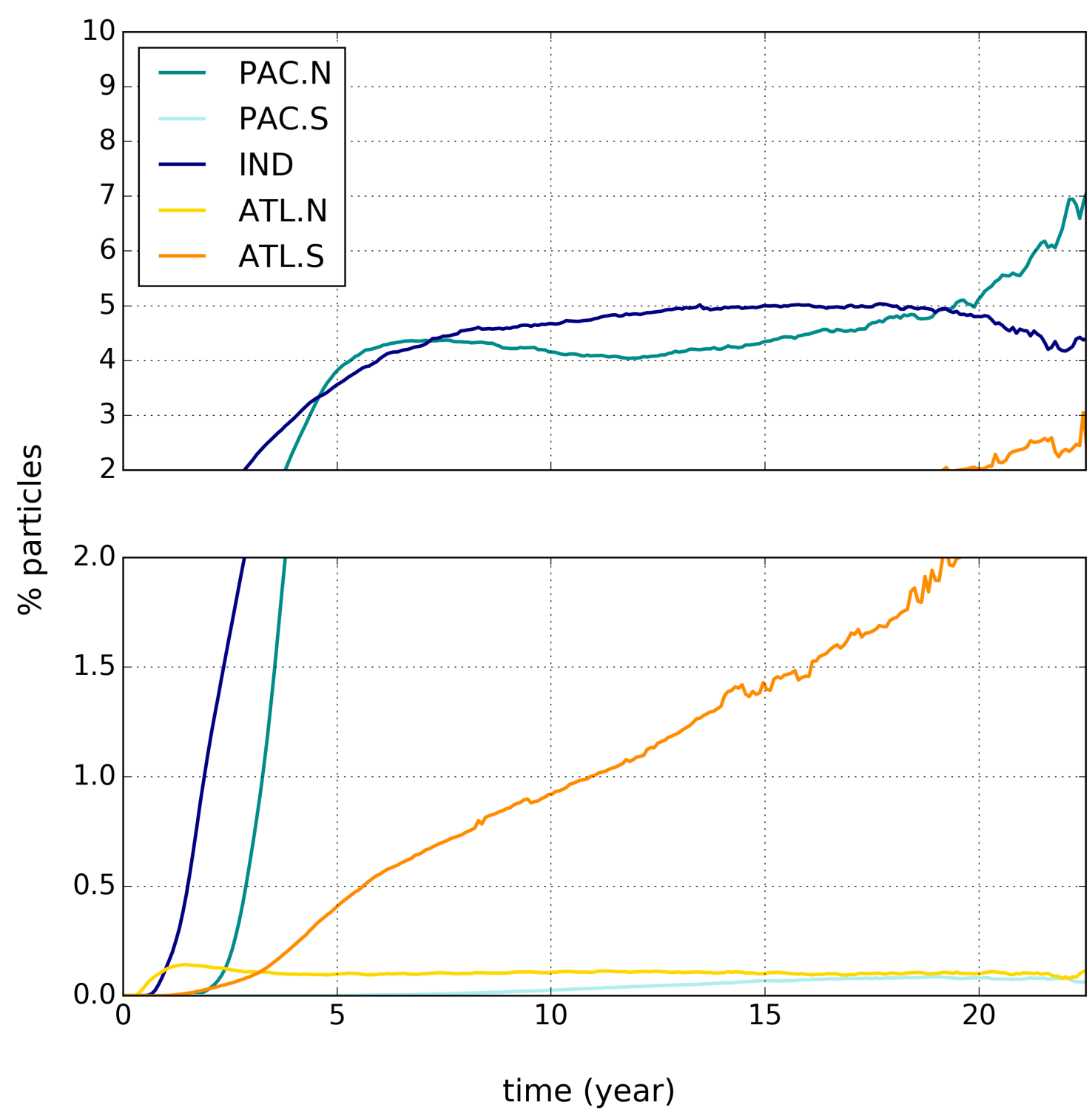

POPULATION

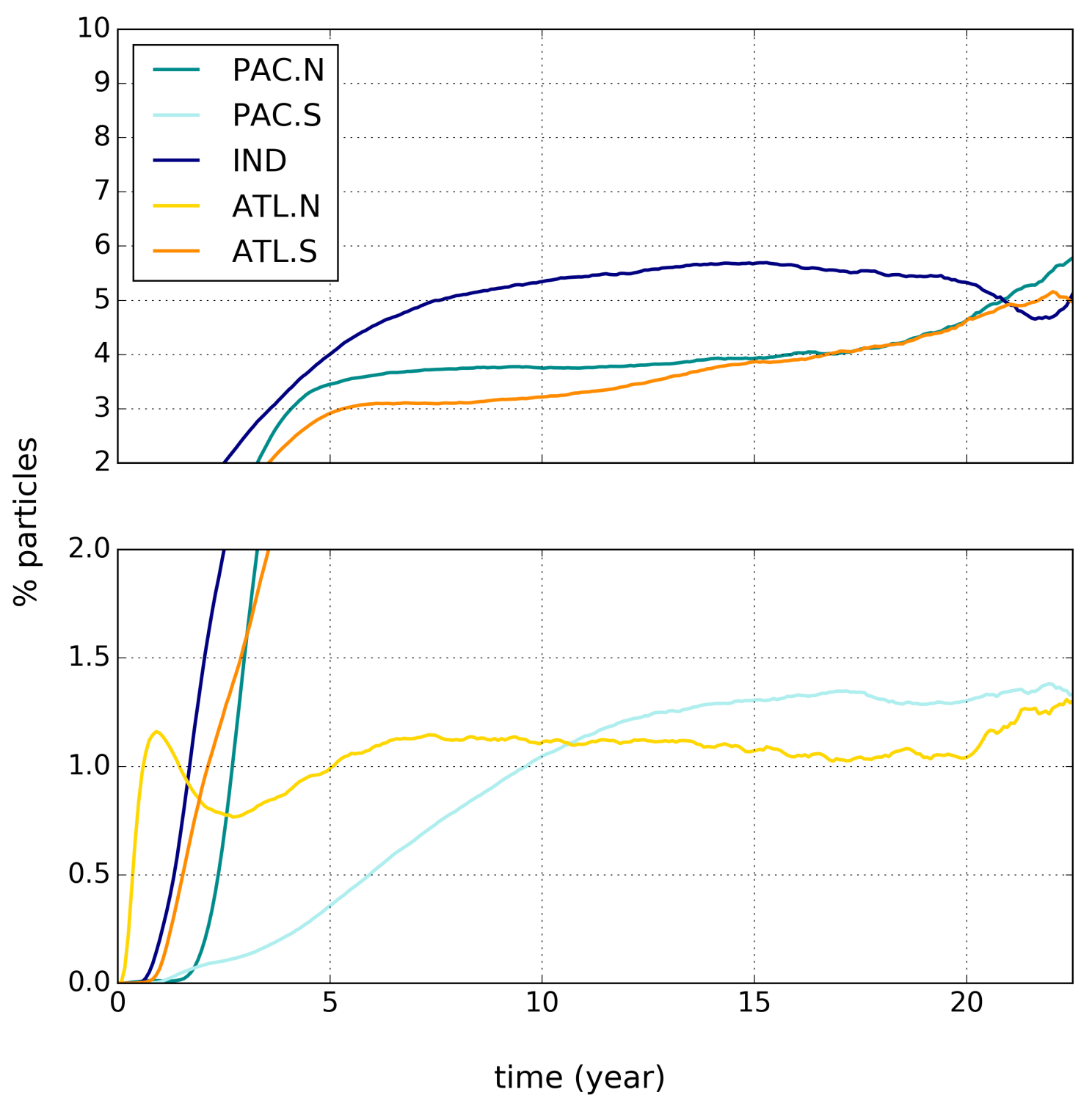

Fig. 4: Percentage of particles in each CVZ center, as a function of simulation time in the river scenario (two upper panels) and the population scenario (i.e., mismanaged waste from the coastal population) (two lower panels). The percentage represents the number of particles in each CVZ normalized by the number of active particles, i.e., the number of particles released at time $t$ since the beginning of the simulation (note that this number of active particles increases each month, as explained in section $2 b$ ). 


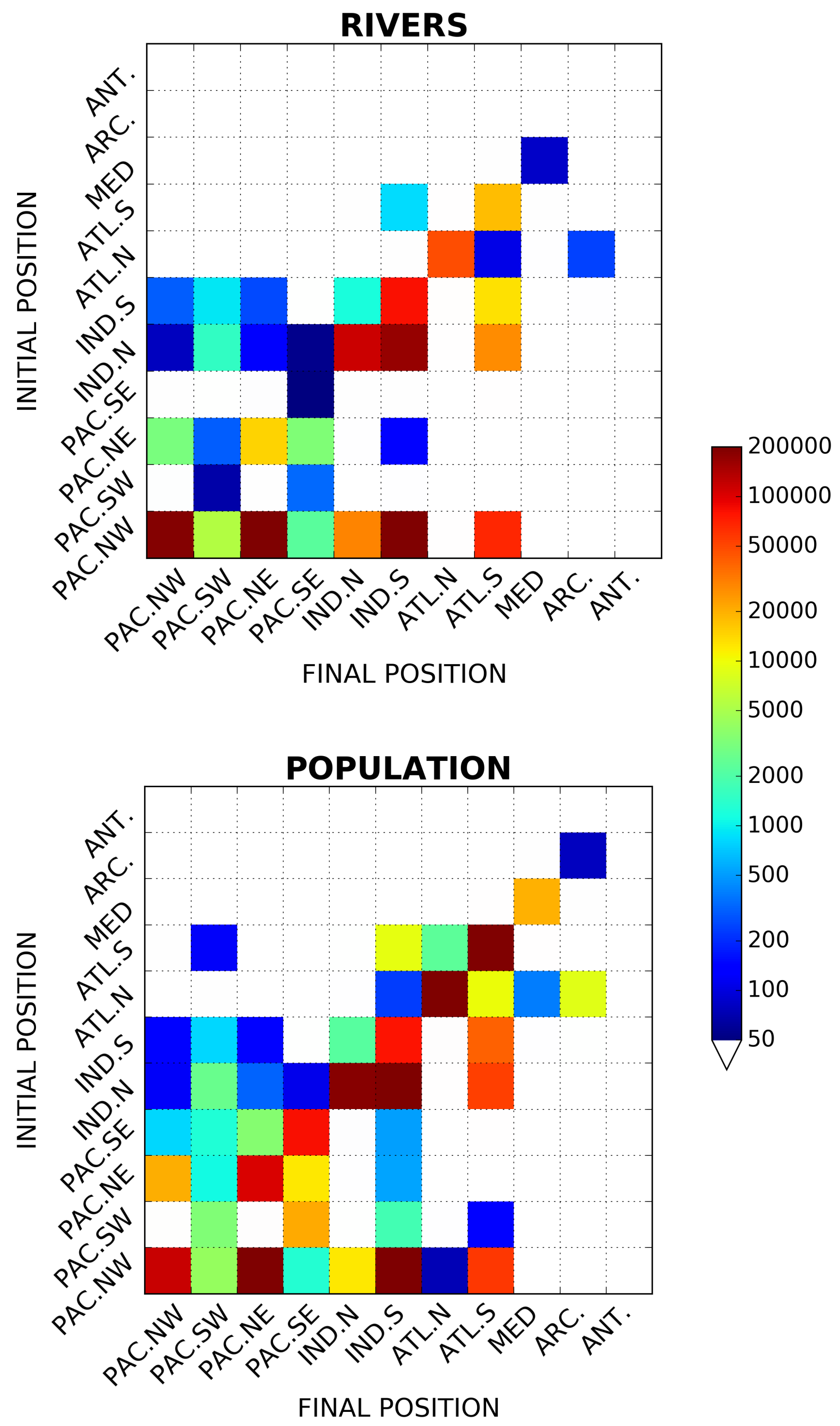

Fig. 5: Connectivity matrix for particles that end up in the sea (case a), in the river (top) and population (i.e., mismanaged waste from the coastal population) (bottom) scenarios. The cells are colored according to the number of particles originating from the region indicated on the $y$-axis and ending up in the region indicated on the x-axis. White cells indicate low connectivity (fewer than 50 particles). 

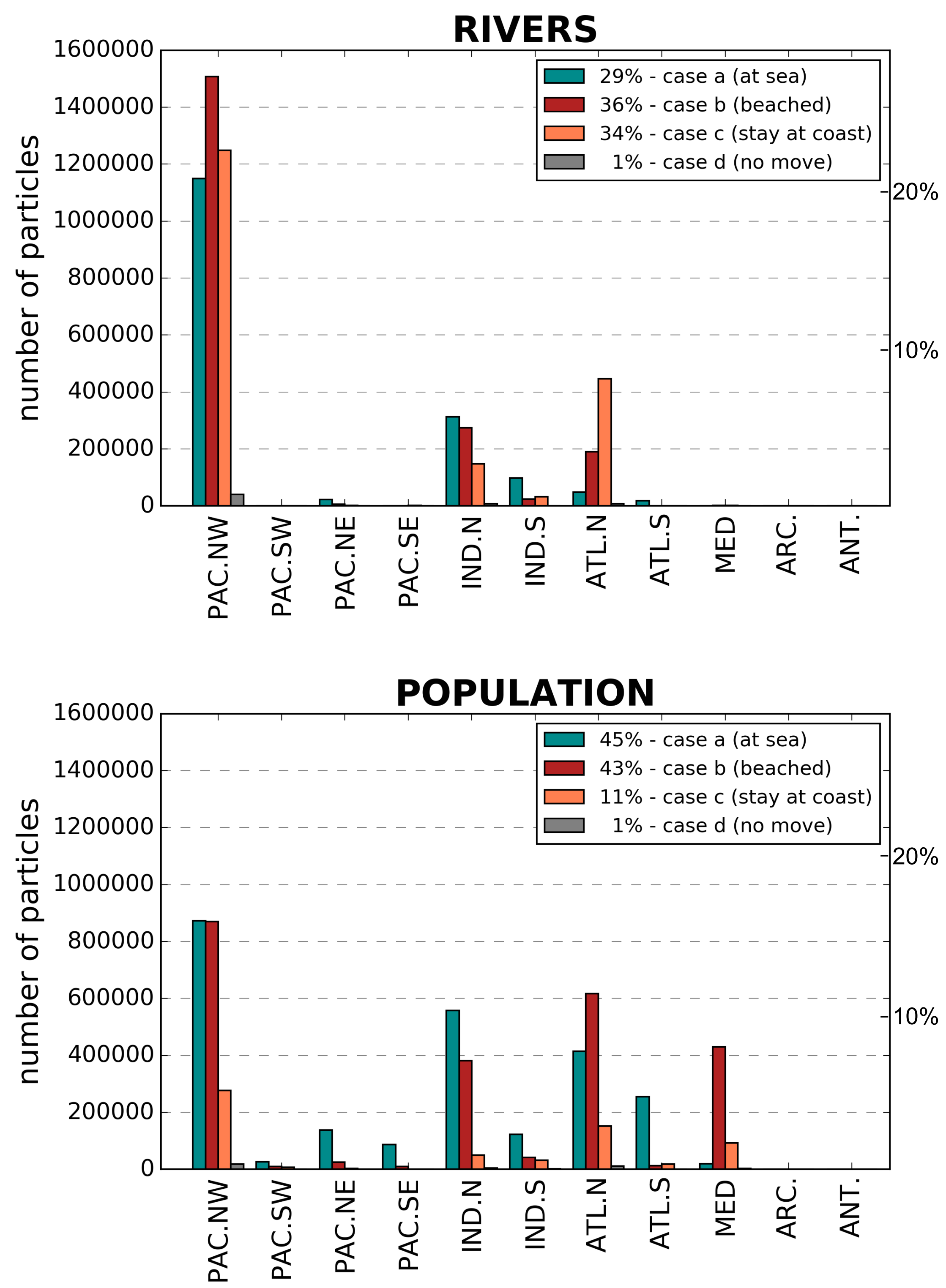

Fig. 6: Histogram of the fates of particles according to their initial region in the Lagrangian experiments (as in Figure 1): particles ending at sea (cases a), beached particles (case b), particles remaining along the coast (case c) or particles that do not move (case d), in the river scenario (top) and the population scenario (i.e., mismanaged waste from the coastal population) (bottom). Percentages on the right are given relatively to the total particles released. 

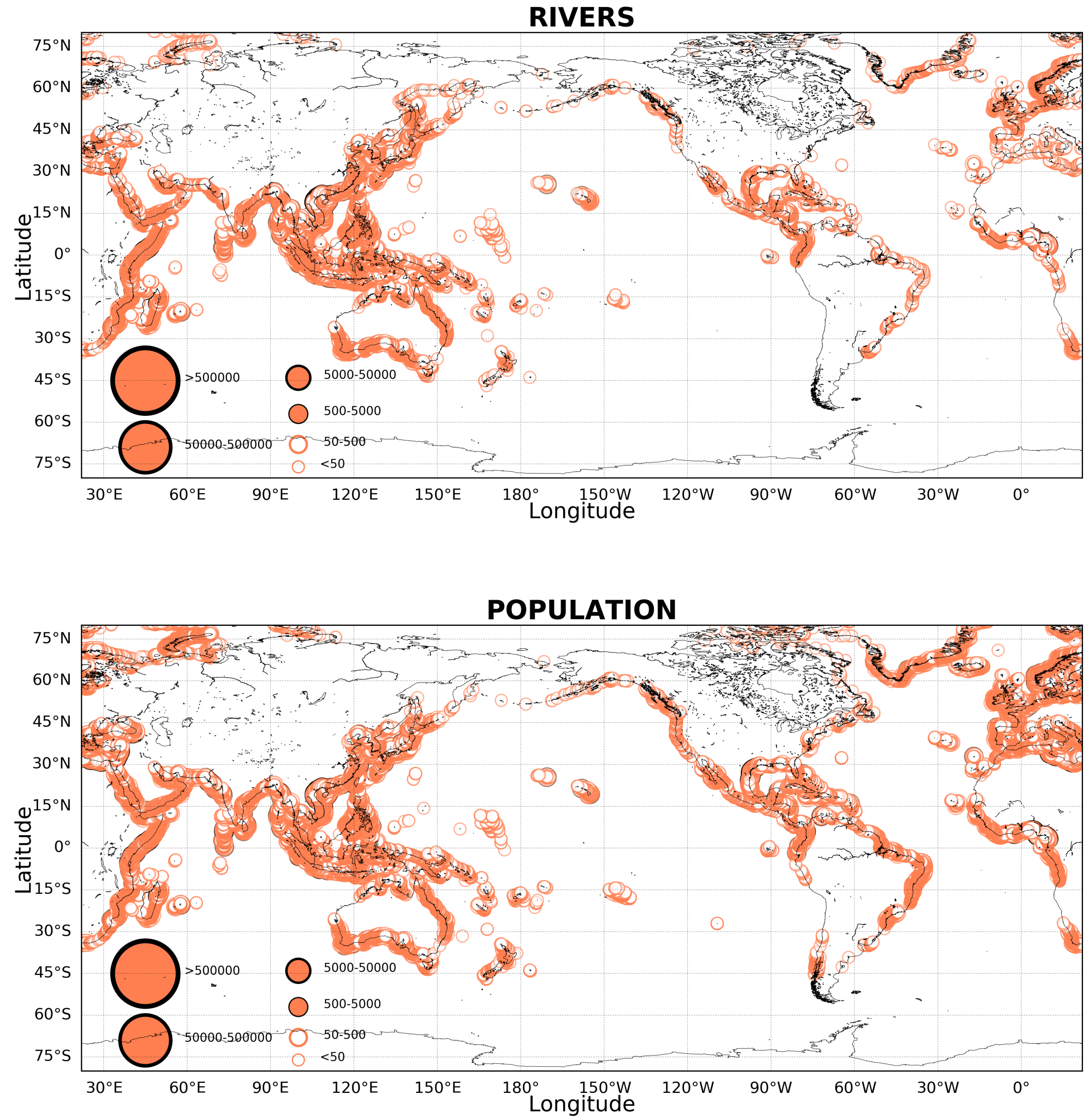

Fig. 7: Number of beached particles (case b) in each coastal grid cell at the end of the simulation (year 23) in the river scenario (top) and the population scenario (i.e., mismanaged waste from the coastal population) (bottom). 


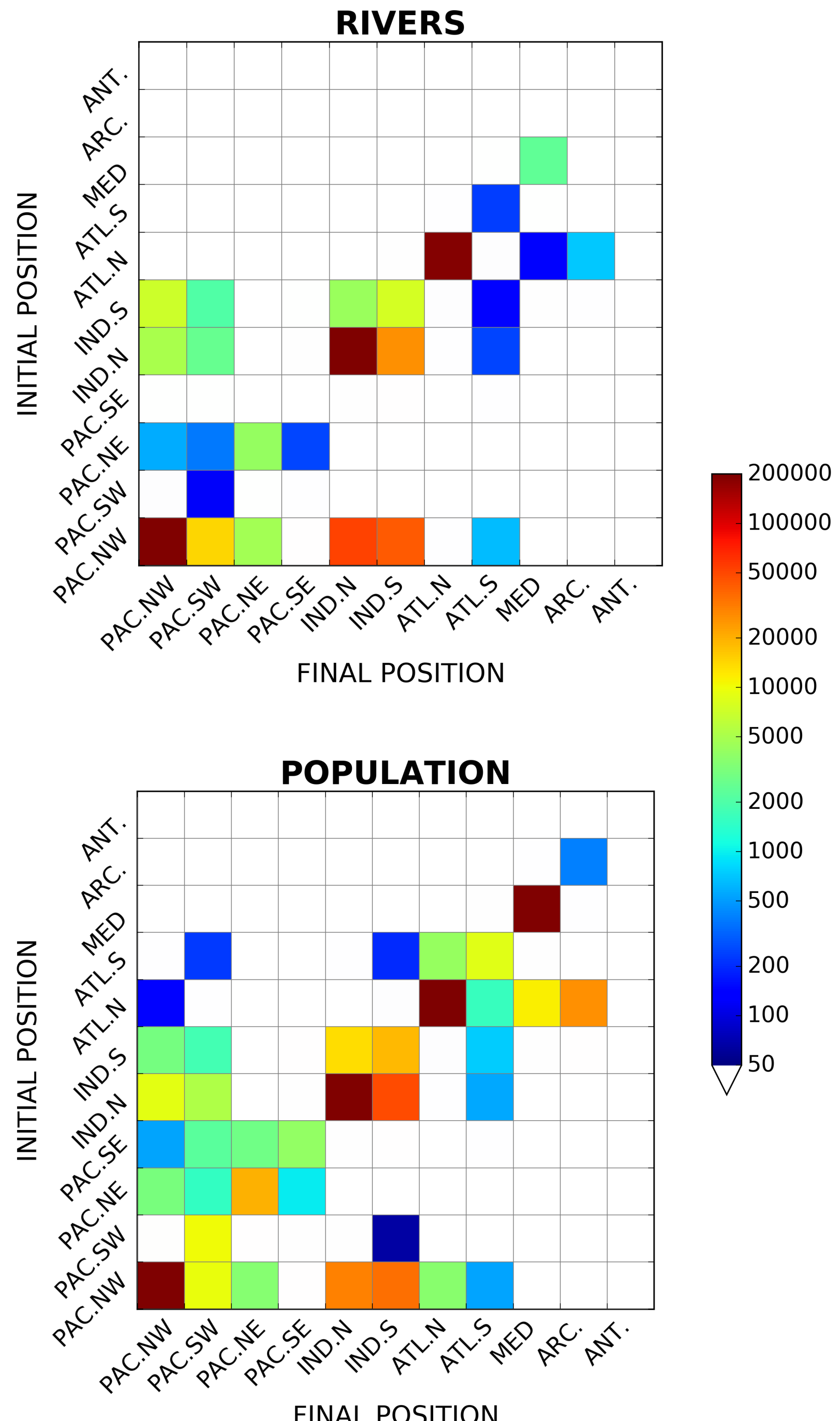

Fig. 8: Connectivity matrix for beached particles (case b) in the river (top) and population (i.e., mismanaged waste from the coastal population) (bottom) scenarios. The cells are colored according to the number of particles originating from the region indicated on the $y$-axis and ending up in the region indicated on the $x$-axis. White cells indicate low connectivity (fewer than 50 particles). 

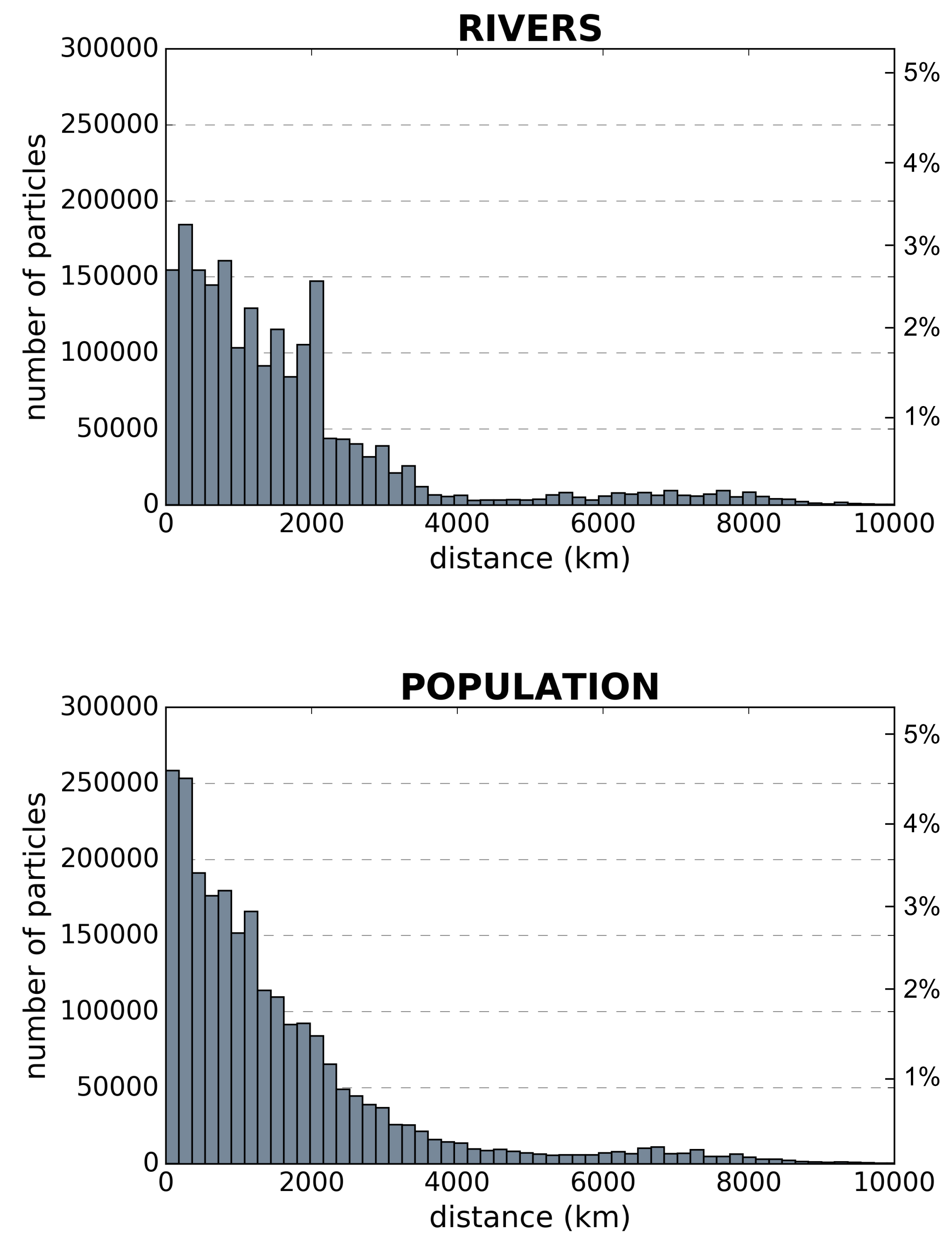

Fig. 9: Histogram of the distances traveled by beached particles (case $b$ ) in the river scenario (top, 2,400,151 beached particles in case b) and population scenarios (i.e., mismanaged waste from the coastal population) (bottom, $2,003,808$ beached particles in case $b$ ). Distances are computed between the initial position and the beached position (see details in section 4). Percentages on the right are given relatively to the total particles released. 

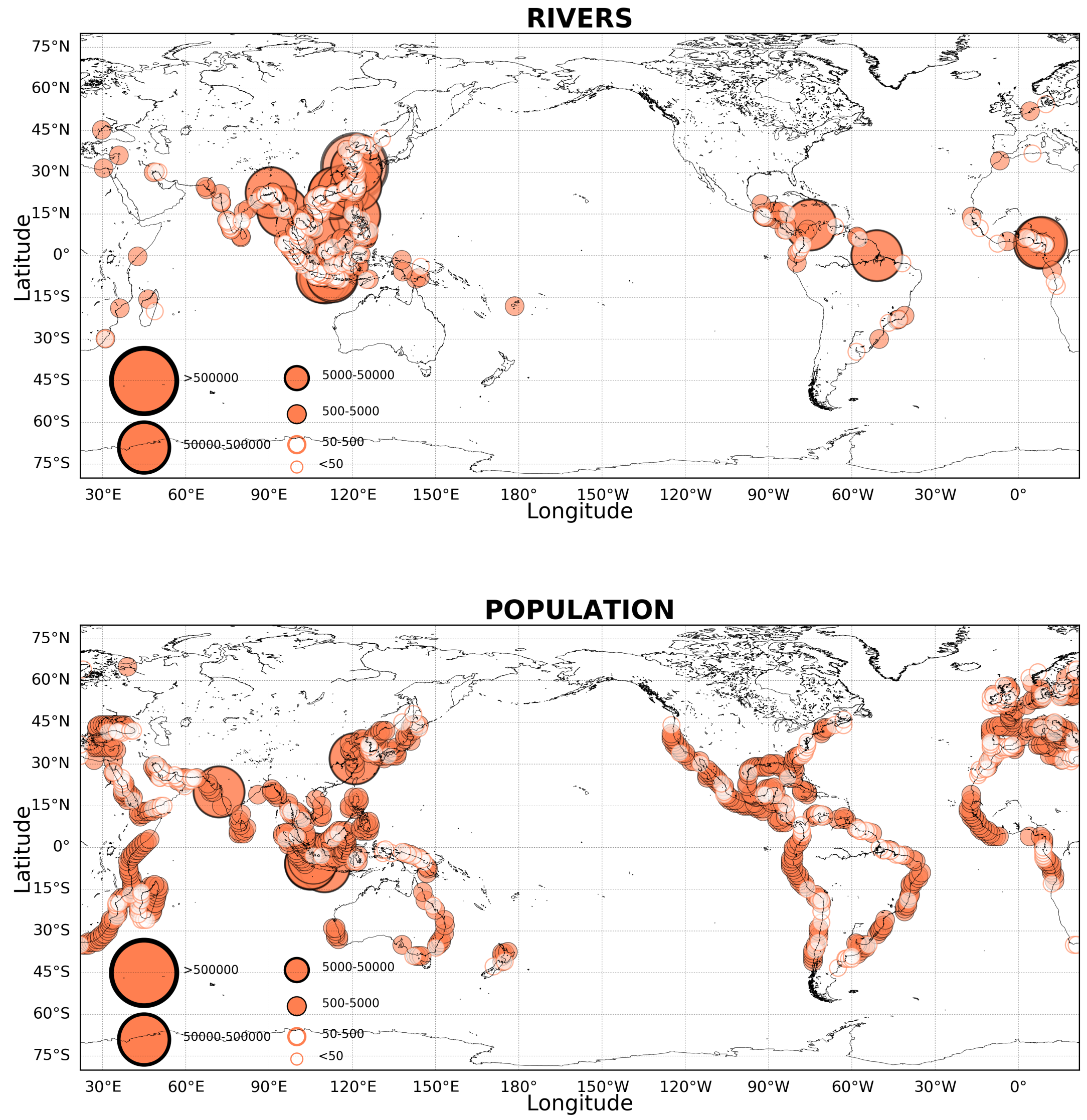

Fig. S1: Number of particles released in each model grid cell in the river scenario (top) and in the population scenario (i.e., mismanaged waste from the coastal population) (bottom). A total of 5,589,080 and 5,571,720 particles are released in the river scenario and the population scenario, respectively. 


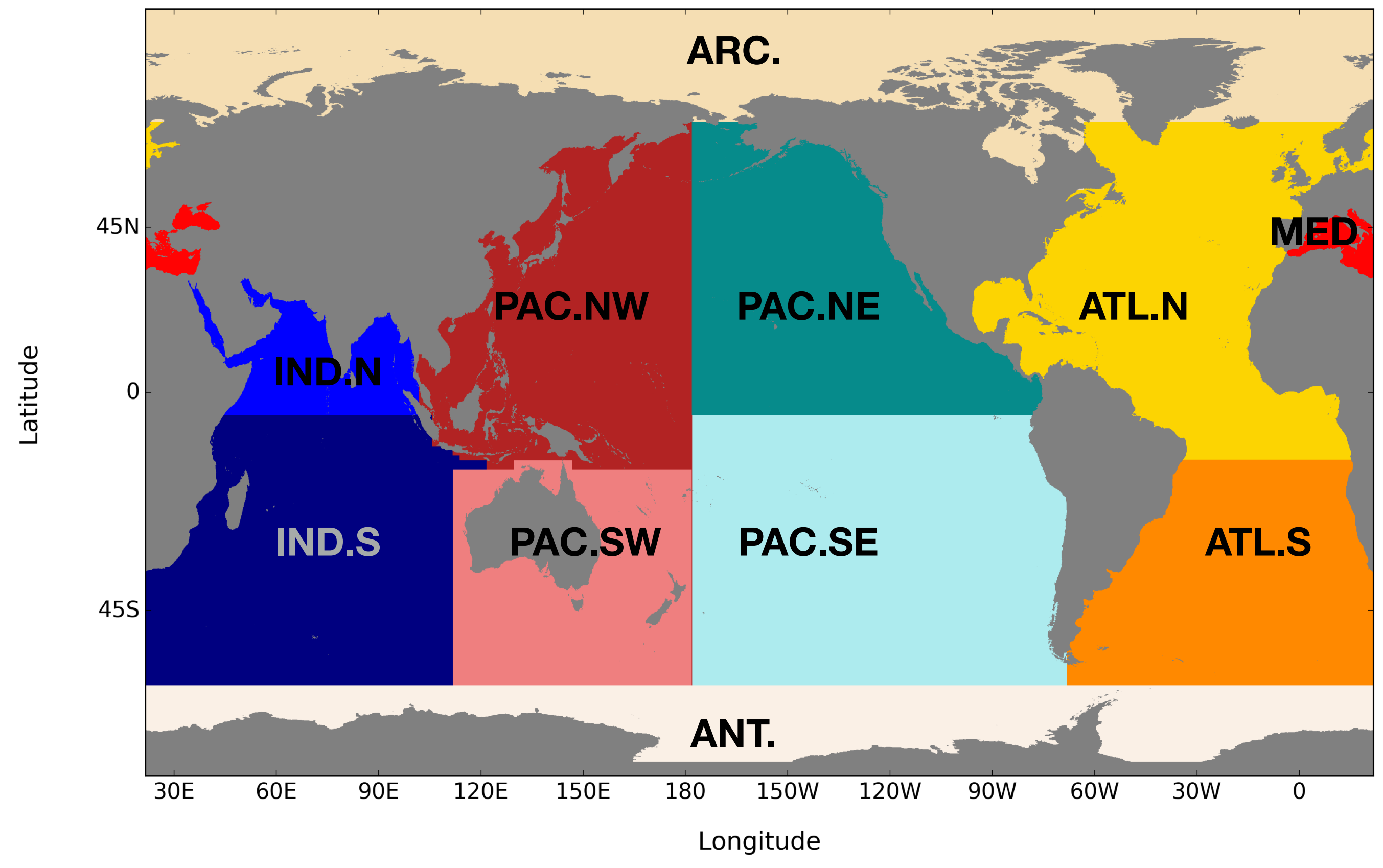

Fig. S2: Definition of the 11 oceanic regions. Note that our definition of the Southwest Pacific actually represents Oceania, and includes the extreme eastern Indian Ocean. 


\section{RIVERS}
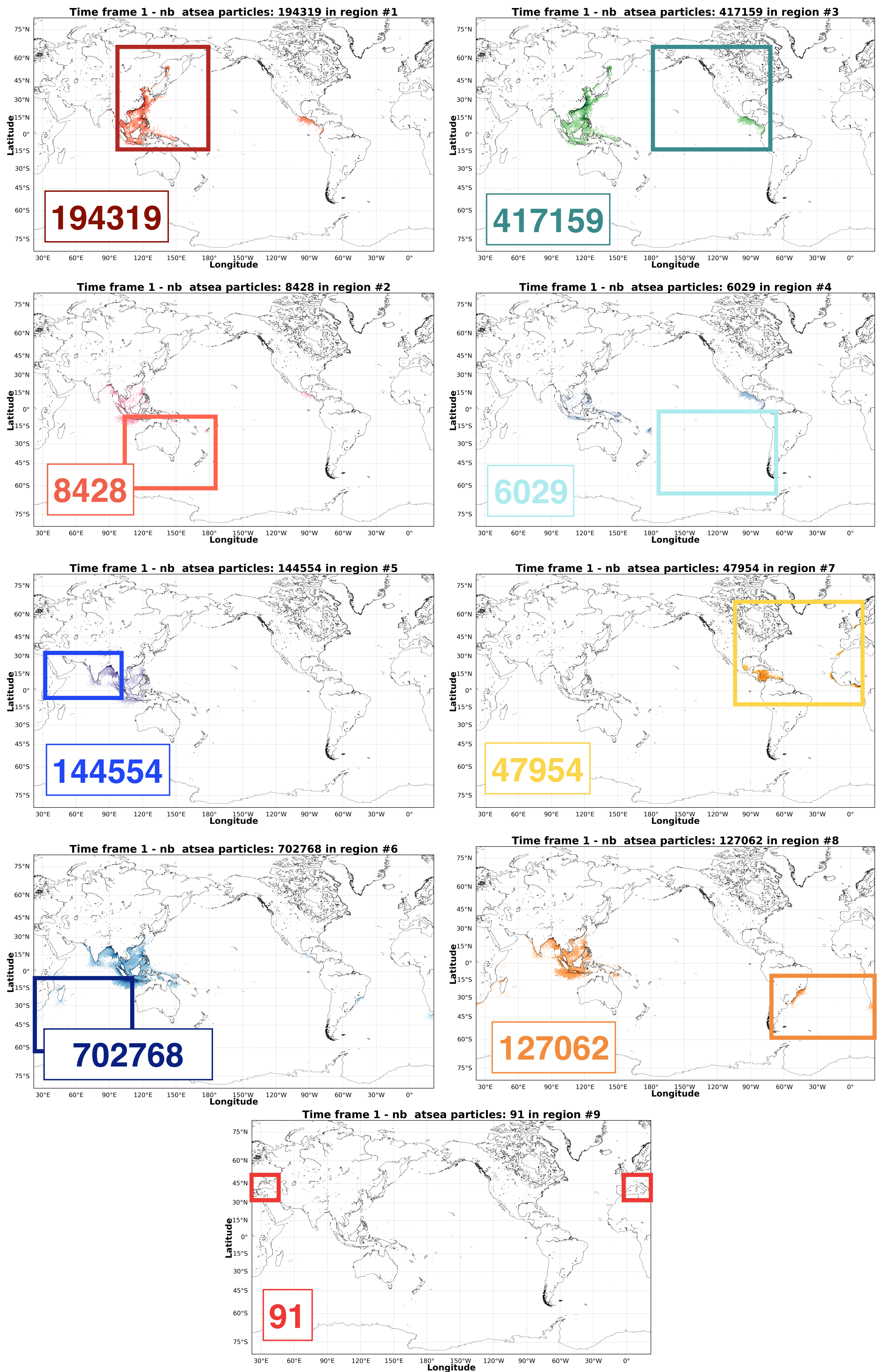

Fig. S3: Near-initial position (1-month after release) of particles ending at sea (case a) in the different oceanic regions in the river scenario. The number of particles is given in the lower left box for each panel. 


\section{POPULATION}
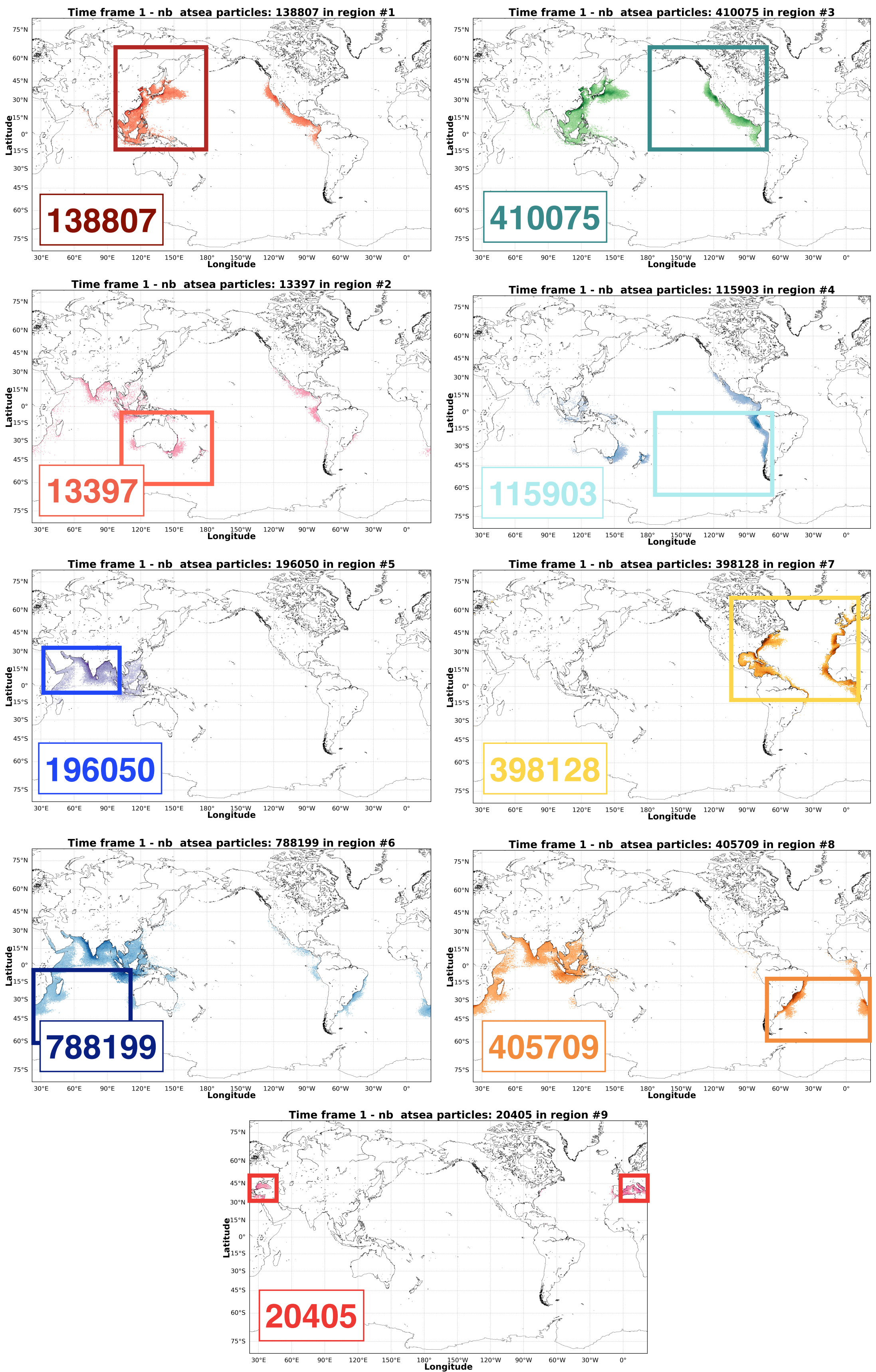

Fig. S4: Near-initial position (1-month after release) of the particles ending at sea (case a) in the different oceanic regions in the population scenario (i.e., mismanaged waste from the coastal population). The number of particles is given in the lower left box for each panel. 


\section{RIVERS SCENARIO}

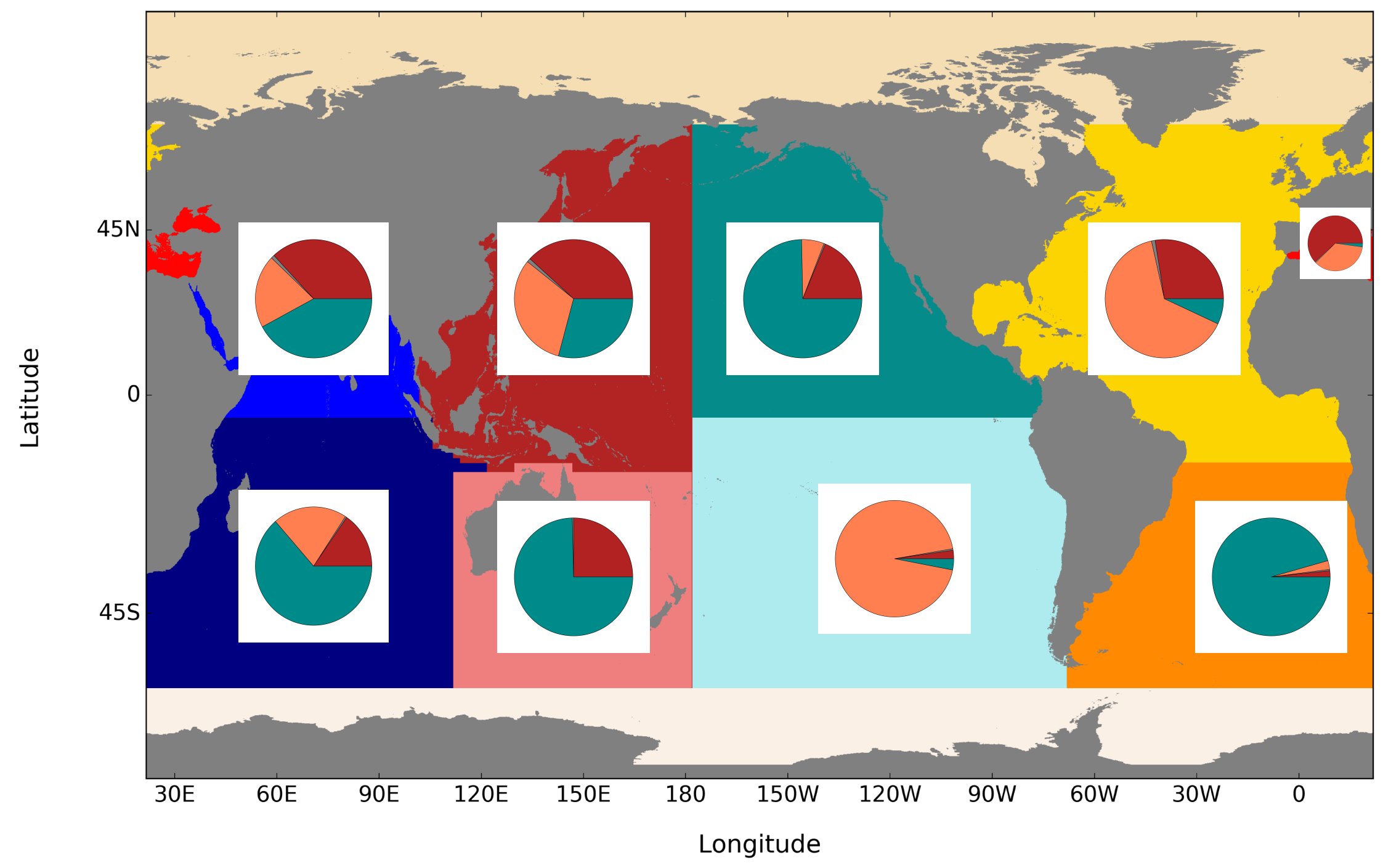

POPULATION SCENARIO

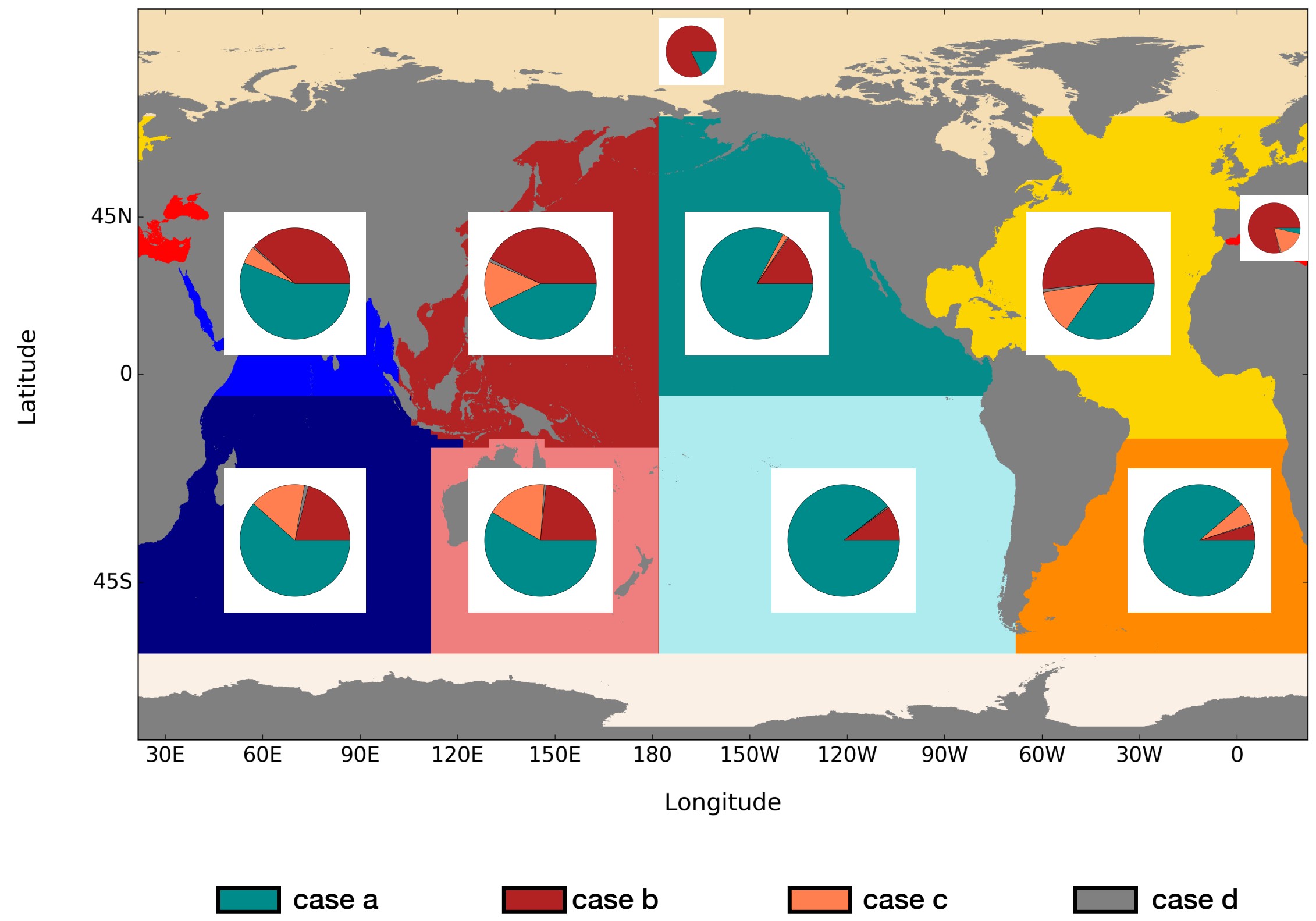

Fig. S5: Pie chart of the fate of particles in cases a (particles ending at sea, in green), $b$ (beached particles, in red), c (particles remaining along the coast, in orange) and $d$ (particles that do not move, in gray) as a function of their initial position in the different oceanic regions (defined in Fig. S2) in the river scenario (top) and the population scenario (i.e., mismanaged waste from the coastal population) (bottom). 


\section{RIVERS}
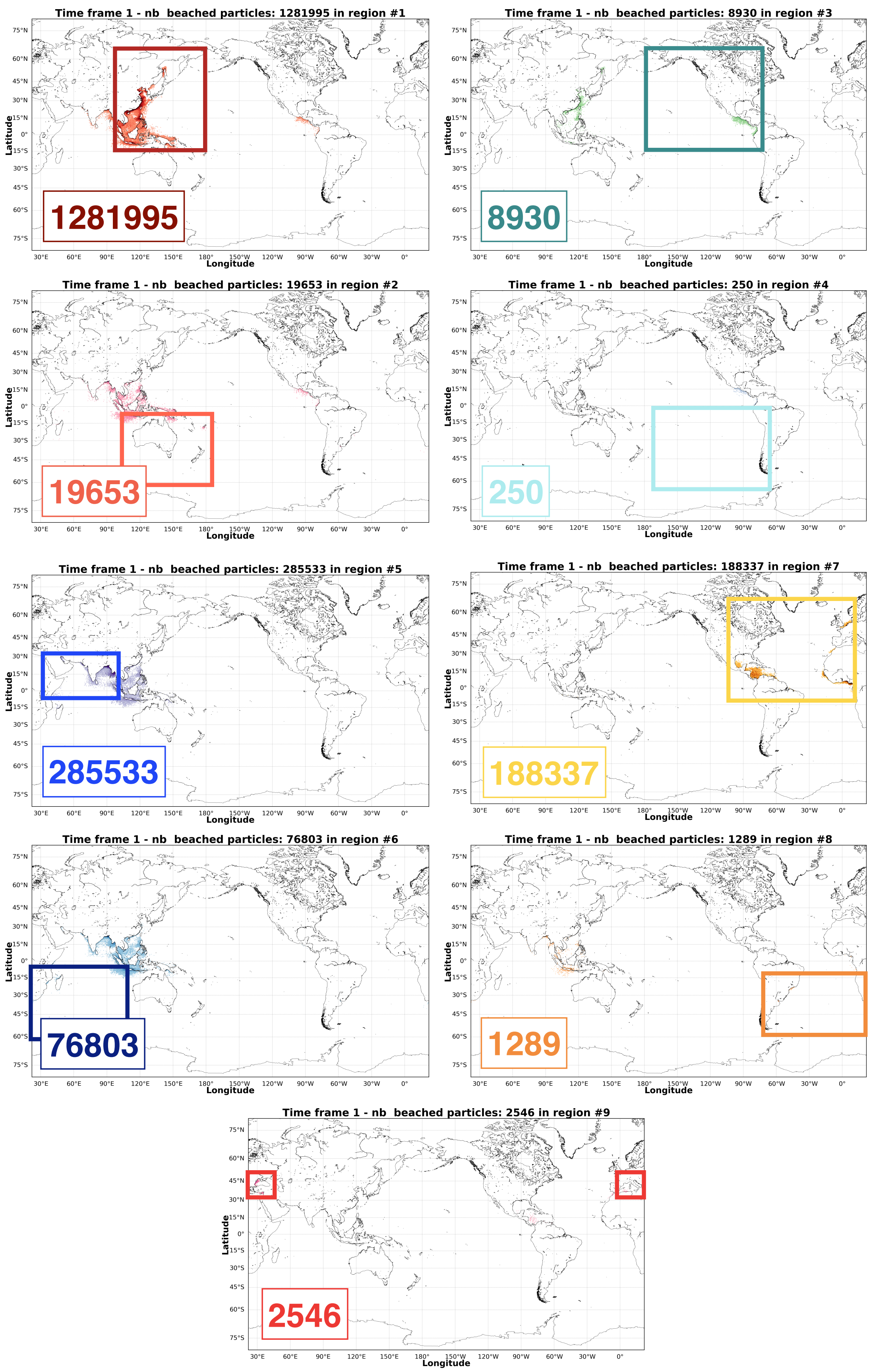

Fig. S6: Near-initial position (1-month after release) of the beached particles (case $b$ ) in the different oceanic regions in the river scenario. The number of particles is given in the lower left box for each panel. 


\section{POPULATION}
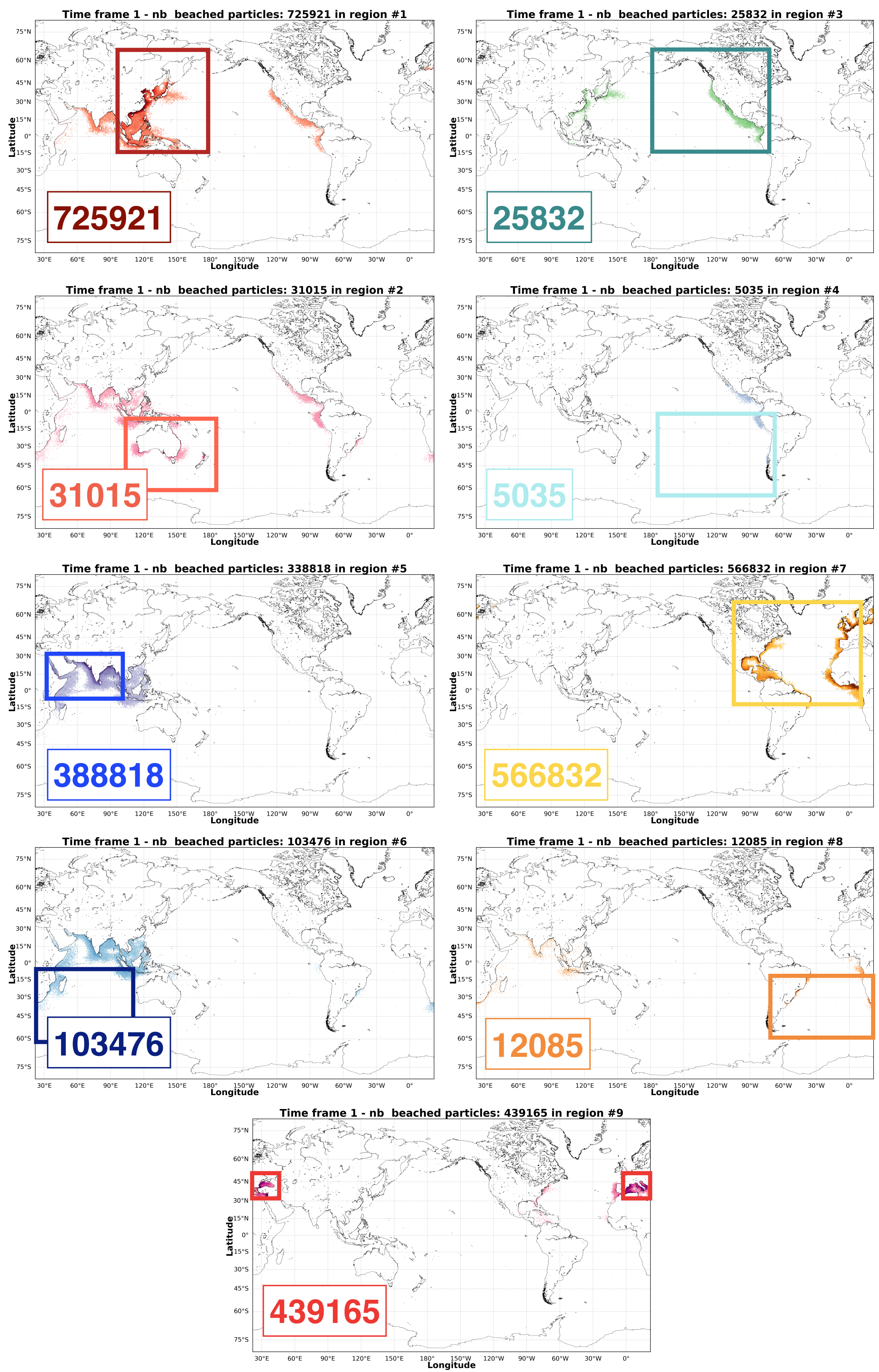

Fig. S7: Near-initial position (1-month after release) of the beached particles (case b) in the different oceanic regions in the population scenario (i.e., mismanaged waste from the coastal population). The number of particles is given in the lower left box for each panel. 

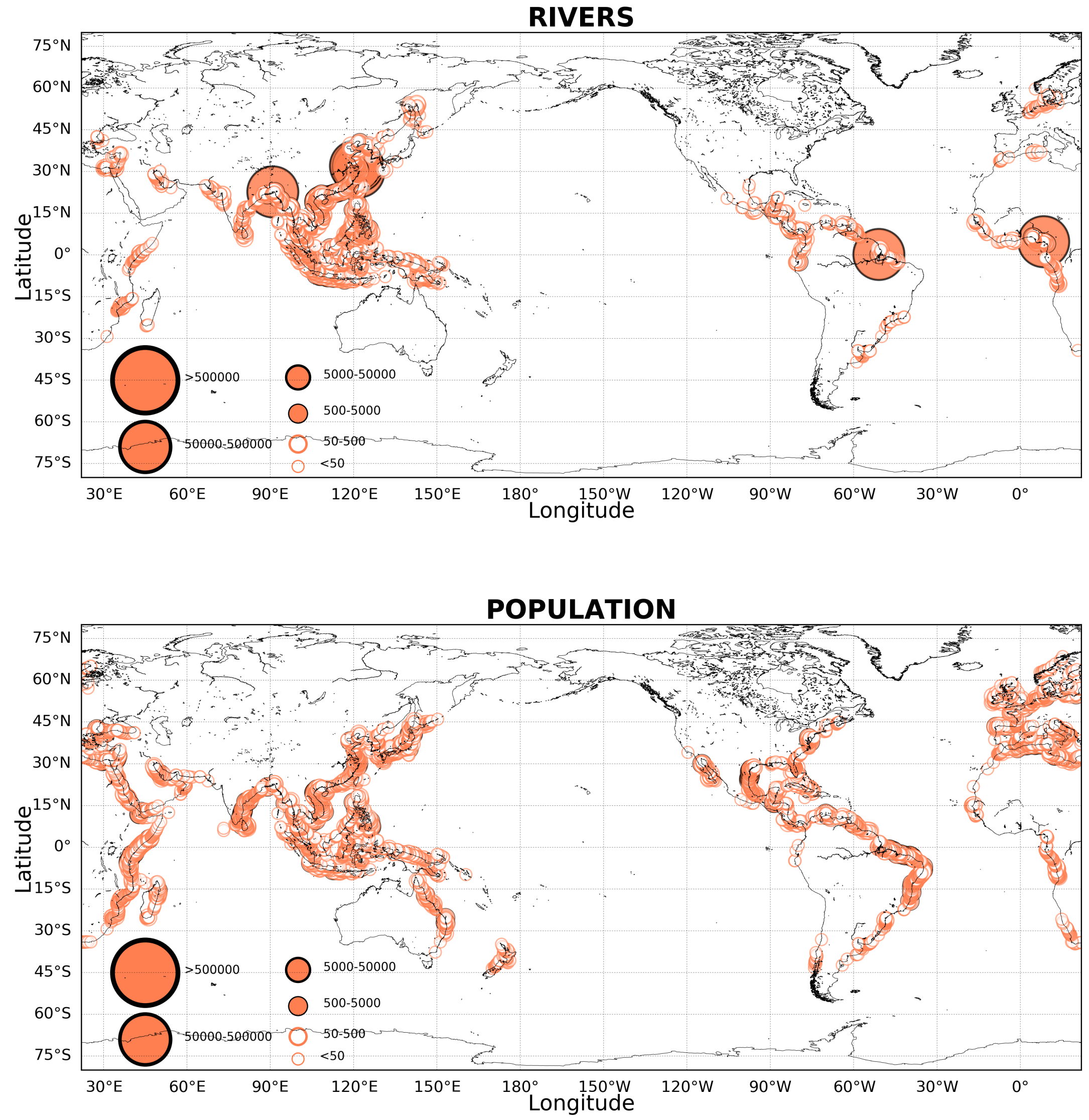

Fig. S8: Number of particles remaining on the shore (case c) in each coastal grid cell at the end of the simulation (year 23) in the river scenario (top) and the population scenario (i.e., mismanaged waste from the coastal population) (bottom). 


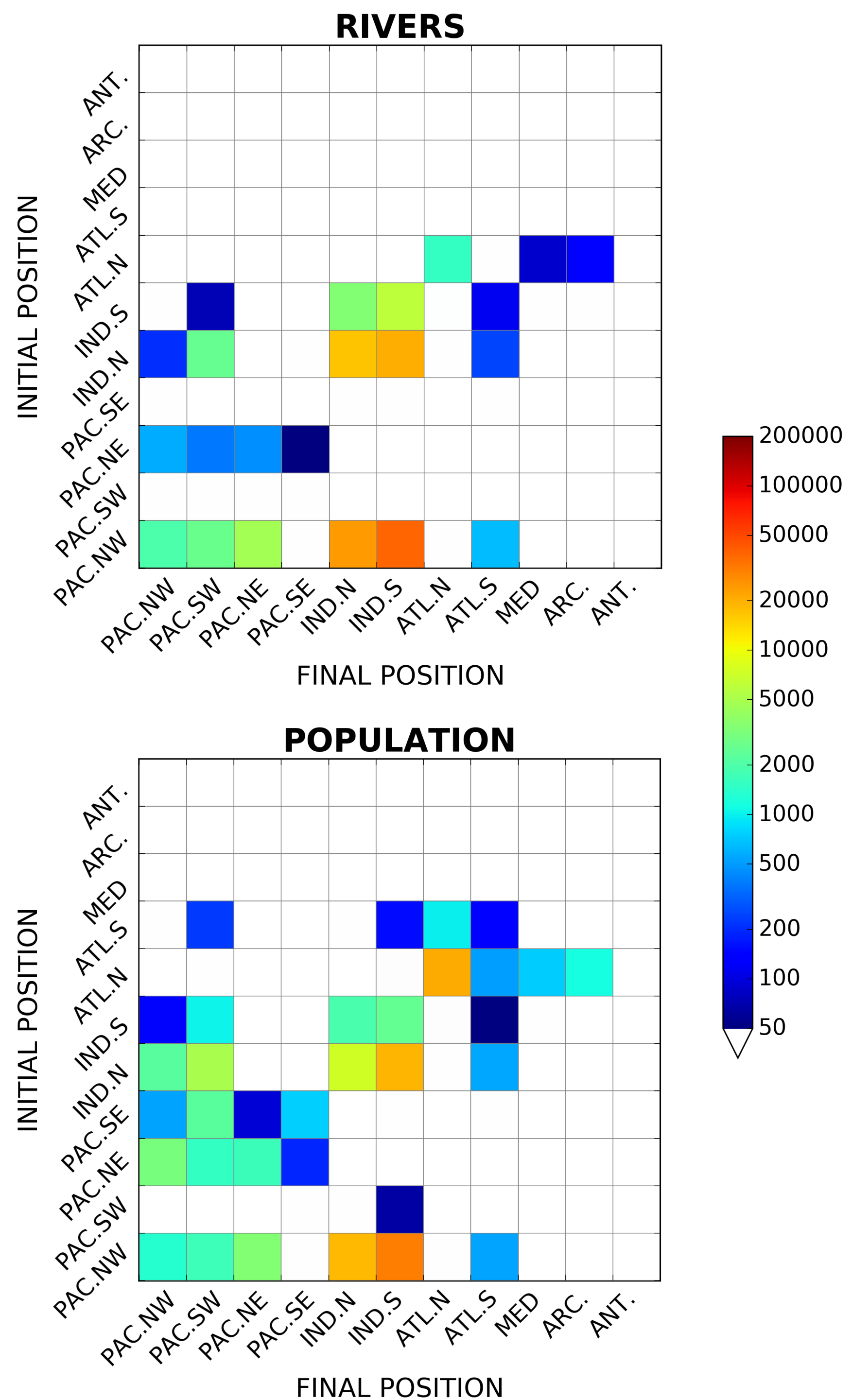

Fig. S9: Connectivity matrix for beached particles that have traveled a long distance, i.e., $>5000 \mathrm{~km}$ (sub-selection from case b) at the end of the simulation (year 23) in the river (top) and population (bottom) scenarios. Cells are colored according to the number of particles originating from the region indicated on the $y$-axis and ending up in the region indicated on the $x$-axis. White cells indicate low connectivity (fewer than 50 particles). 